Review

\title{
The Oscillatory Spinning Drop Technique. An Innovative Method to Measure Dilational Interfacial Rheological Properties of Brine-Crude Oil Systems in the Presence of Asphaltenes
}

\author{
Ronald Marquez *(D), Johnny Bullon*(D), Ana Forgiarini *(D) and Jean-Louis Salager *(D) \\ Laboratorio FIRP, Universidad de Los Andes, Mérida 5101, Venezuela \\ * Correspondence: marquezronald.ula.ve@gmail.com (R.M.); jbullontorr@gmail.com (J.B.); \\ anafor.ula@gmail.com (A.F.); jl.salager@gmail.com (J.-L.S.)
}

check for updates

Citation: Marquez, R.; Bullon, J.; Forgiarini, A.; Salager, J.-L. The Oscillatory Spinning Drop Technique. An Innovative Method to Measure Dilational Interfacial Rheological Properties of Brine-Crude Oil Systems in the Presence of Asphaltenes. Colloids Interfaces 2021, 5, 42. https:/ / doi.org/10.3390/colloids5030042

Academic Editors: Volodymyr I. Kovalchuk and Giuseppe Loglio

Received: 11 June 2021

Accepted: 26 July 2021

Published: 4 August 2021

Publisher's Note: MDPI stays neutral with regard to jurisdictional claims in published maps and institutional affiliations.

Copyright: (c) 2021 by the authors. Licensee MDPI, Basel, Switzerland. This article is an open access article distributed under the terms and conditions of the Creative Commons Attribution (CC BY) license (https:// creativecommons.org/licenses/by/ $4.0 /)$.

\begin{abstract}
The oscillatory spinning drop method has been proven recently to be an accurate technique to measure dilational interfacial rheological properties. It is the only available equipment for measuring dilational moduli in low interfacial tension systems, as it is the case in applications dealing with surfactant-oil-water three-phase behavior like enhanced oil recovery, crude oil dehydration, or extreme microemulsion solubilization. Different systems can be studied, bubble-in-liquid, oil-in-water, microemulsion-in-water, oil-in-microemulsion, and systems with the presence of complex natural surfactants like asphaltene aggregates or particles. The technique allows studying the characteristics and properties of water/oil interfaces, particularly when the oil contains asphaltenes and when surfactants are present. In this work, we present a review of the measurements of crude oil-brine interfaces with the oscillating spinning drop technique. The review is divided into four sections. First, an introduction on the oscillating spinning drop technique, fundamental and applied concepts are presented. The three sections that follow are divided according to the complexity of the systems measured with the oscillating spinning drop, starting with simple surfactant-oil-water systems. Then the complexity increases, presenting interfacial rheology properties of crude oil-brine systems, and finally, more complex surfactant-crude oil-brine systems are reviewed. We have found that using the oscillating spinning drop method to measure interfacial rheology properties can help make precise measurements in a reasonable amount of time. This is of significance when systems with long equilibration times, e.g., asphaltene or high molecular weight surfactant-containing systems are measured, or with systems formulated with a demulsifier which is generally associated with low interfacial tension.
\end{abstract}

Keywords: interfacial rheology; spinning drop; crude oil; asphaltenes; dilational; compression; elasticity; Gibbs-Marangoni

\section{Introduction}

The spinning drop technique has been extensively used to study surfactant-oil-water (SOW) systems since the 1970s when it was used at the University of Texas to measure the very low interfacial tension required for enhanced oil recovery (EOR) [1-4]. Vonnegut [5] demonstrated in a pioneering work the theoretical basis for the measurement, based on the geometry of an elongated liquid drop, which is located inside a rotating capillary containing the other liquid phase. Equation (1) was proposed to calculate the interfacial tension for an elongated quasi-cylindrical drop [6]:

$$
\gamma=\Delta \rho \omega_{\text {rot }}^{2} \mathrm{~d}^{3} / 32
$$

where $\gamma$ is the interfacial tension in $\mathrm{mN} / \mathrm{m}, \mathrm{d}$ is the cylindrical droplet diameter in $\mathrm{mm}, \Delta \rho$ is the difference of the densities of the two phases in $\mathrm{g} / \mathrm{mL}$, and $\omega_{\text {rot }}$ the angular velocity 
in rev/msec [7]. These parameters are depicted schematically in Figure 1. The method consists of placing the surfactant-oil-water systems in test tubes at a known water-oil relationship (usually WOR $=1$ ) and then pre-equilibrate before the tension measurement (at least for $24 \mathrm{~h}$ ) [2,8]. Then, the continuous (denser) and dispersed (less dense) phases are placed inside the capillary, which is inserted in the spinning drop tensiometer.

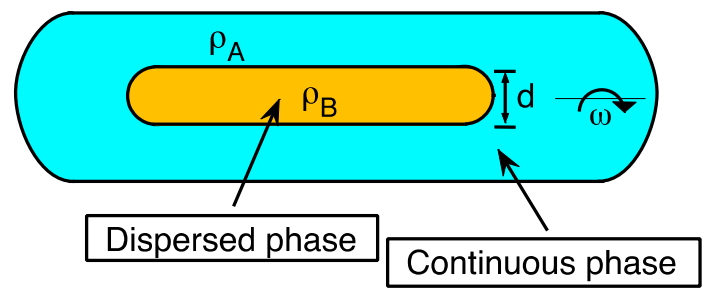

Figure 1. Spinning drop in the tensiometer capillary indicating the parameters necessary to calculate interfacial tension: the densities of the two phases $\rho_{A}$ and $\rho_{B}$, the drop diameter $d$, and the rotational velocity $\omega_{\text {rot }}$.

This method is particularly interesting because it can measure very low interfacial tensions (lower than $1 \mathrm{mN} / \mathrm{m}$ ), which cannot be performed in the simples Du Nouy ring or Wilhelmy plate methods. In sophisticated pendant drop equipment, often used in laboratories, the droplet detaches from the needle at interfacial tensions lower than $1 \mathrm{mN} / \mathrm{m}$, thus excluding such apparatus from oscillating methods $[9,10]$.

Interfacial rheology techniques are based mainly on shear and compression deformations [11-13] when an oscillatory perturbation is applied to the system. Dilational interfacial rheology studies have been mostly reported with pendant drop methods [14-16]. The technique consists of a drop driven out and sucked in at the end of a vertical capillary needle to expand and contract its area, thus changing the area and also the drop's volume.

The oscillating spinning drop equipment was built recently in the FIRP laboratory with the collaboration of the CITEC-ULA workshop, based on the oscillatory deformation of a spinning drop [7]. This apparatus can be used to perform interfacial rheology measurements of both low and ultralow interfacial tensions (as low as $10^{-4} \mathrm{mN} / \mathrm{m}$ ). This is critical when the formulation is at or close to optimum [17-19], such as in enhanced oil recovery or crude dehydration applications [20,21].

The current model, shown in Figure 2, includes a spinning capillary with a $4 \mathrm{~mm}$ internal diameter coupled to a motor and a transducer. The capillary rotates at a velocity, which is controlled by a PID unit. The drop area is changed by varying the rotational speed sinusoidally at frequencies between 0.015 and $0.25 \mathrm{~Hz}$. The device automatically takes pictures at desired time intervals (down to $0.05 \mathrm{~s}$ ). Each image allows determining the droplet diameter, which is automatically recorded together with the rotational velocity. Then, the droplet diameter and the rotational velocity are used to calculate the interfacial tension from the simplified Vonnegut equation [7].

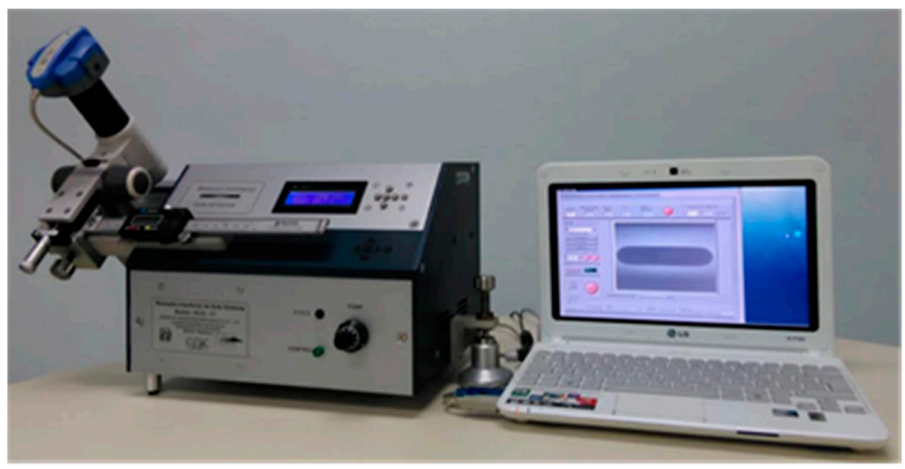

Figure 2. Oscillating spinning drop interfacial rheometer recent version. 


\subsection{Dilational Interfacial Rheology}

In interfacial rheology measurements, the dilational modulus is calculated as:

$$
\mathrm{E}=\mathrm{A} \delta \Pi / \delta \mathrm{A}
$$

where $A$ is the superficial area and $\Pi$ is the surface pressure, which is $\Pi=\gamma_{0}-\gamma$ the interfacial tension difference between a clean interface and an interface in the presence of a surfactant [10]. $\Gamma \sim 1 / \mathrm{A}$ :

For an insoluble monolayer, the surface surfactant concentration can be expressed as

$$
\mathrm{E}=\Gamma \delta \Pi / \delta \Gamma
$$

The modulus $\mathrm{E}$ is also called compression modulus in the literature [13].

When the droplet in the spinning drop equipment is subjected to an oscillatory expansion and contraction of area (A), a response of the interfacial tension $(\gamma)$ can be measured. Thus, the interfacial dilational modulus E can be calculated with Equation (4):

$$
\mathrm{E}=\mathrm{A}_{0} \Delta \gamma / \Delta \mathrm{A}
$$

where $\Delta \gamma\left(=\gamma_{\max }-\gamma_{\min }\right)$ is the change in the amplitude of the interfacial tension. $\Delta \mathrm{A}$ (= $\left.\mathrm{A}_{\max }-\mathrm{A}_{\min }\right)$ is the amplitude of variation of the area, and $\mathrm{A}_{0}$ is the initial interfacial area of the drop.

The dilational modulus can also be expressed as the complex number shown in Equation (5) that includes both the elastic (or storage modulus E') and viscous (or loss modulus $\left.\mathrm{E}^{\prime \prime}\right)$ contributions:

$$
E=E^{\prime}+i E^{\prime \prime}
$$

In viscoelastic interfaces, $\gamma$ and A variations measured at a frequency $\omega$, result in an occurring time shift, represented by the phase angle $\Phi$. $E^{\prime}$ and $E^{\prime \prime}$ account for the energy stored and the energy dissipation through relaxation processes, respectively. They can be obtained from the phase angle through Equations (6) and (7):

$$
\begin{aligned}
& \mathrm{E}^{\prime}=\mathrm{E} \cos (\Phi) \\
& \mathrm{E}^{\prime \prime}=\mathrm{E} \sin (\Phi)
\end{aligned}
$$

The interfacial viscosity $\eta_{\mathrm{E}}$ can be calculated as:

$$
\eta_{E}=E^{\prime \prime} / \omega
$$

where $\omega$ is the frequency of oscillation.

In previous reports, we have shown the characteristics of the oscillating spinning drop apparatus [7] and its application in simple [17,18] and more complex systems [20,21]. The contents of the present review start with a short introduction of the basic and practical aspects of the oscillatory spinning drop interfacial rheology technique. Then, the characteristics of common systems and specific cases for measurements in crude oil (with asphaltenes)brine and crude oil-surfactant-brine complex systems will be presented and discussed.

\subsection{Basic Aspects of the Oscillating Spinning Drop Interfacial Rheology Technique}

The spinning drop tensiometer with an oscillating rotation velocity is used to measure interfacial compression rheology properties whose principle was proposed 40 years ago [22]. The description of the newly developed equipment was recently reported [7], and it was shown that the apparatus makes accurate and reliable measurements of interfacial rheology parameters at high, low, and ultralow interfacial tensions. The dilational modulus measured with the oscillatory spinning drop apparatus is the Young modulus (EYoung), which in two dimensions has compression and shear contributions, i.e., $\mathrm{E}_{\text {Young }}=\mathrm{E}+\mathrm{G}$. 
Thus, it was recently reported that the measured elastic modulus $E^{\prime}$ values are similar to those found with a pendant drop apparatus [7].

Some original interfacial rheological properties at and near optimum formulation (i.e., at hydrophilic-lipophilic deviation $\mathrm{HLD}_{\mathrm{N}}=0$, with ultralow interfacial tensions), were recently reported for the first time [18]. The systems studied range from low concentration (just above the critical microemulsion concentration $\mathrm{c} \mu \mathrm{c}$ ) to a large middle-phase microemulsion volume. It was systematically found that at $\mathrm{HLD}_{\mathrm{N}}=0$, very low values of the dilational moduli and interfacial viscosity are attained. This occurs probably because the diffusional mass transfer is very fast at $\mathrm{HLD}_{\mathrm{N}}=0$ [23]. Thus, the measurement at $\mathrm{HLD}_{\mathrm{N}}=0$ is an effective dilational (or compression) modulus, which considers the fast surfactant exchanges between the bulk and the interface in WIII systems [17]. This is particularly important because it explains the very deep minimum in emulsion stability at optimum formulation, and consequently, why it should be the selected formulation for enhanced oil recovery, crude oil dehydration, and desalting processes [24-26].

\subsection{Practical Aspects of the Measurement}

The oscillatory spinning drop technique requires specific conditions to be followed to ensure an accurate measurement; the droplet volume, the rotational speed, and the oscillation amplitude must be selected accordingly. Placing a suitable quantity of the internal phase droplet inside the external phase is a tricky operation because, according to the interfacial tension value and the density difference between the fluids, a lower or higher volume droplet should be placed inside the capillary. The droplet aspect also depends on the rotational speed of the interfacial rheometer and of its oscillation amplitude. A higher rotational speed elongates more the droplet, and if it happens, a lower drop volume must be inserted inside the capillary. The recommended drop volume varies from $10-30 \mu \mathrm{L}$ for air-water or oil-water systems to $0.5-5 \mu \mathrm{L}$ for ultralow tension systems. Table 1 indicates typical values for the drop volume, rotational speed and equilibration time. This rationale comes from the experience of thousands of measurements in our laboratory.

Table 1. Typical values of interfacial (or surface) tension, droplet volume, recommended rotational speed, and equilibration time for operation with the oscillatory spinning drop apparatus.

\begin{tabular}{|c|c|c|c|c|}
\hline System & $\begin{array}{c}\text { Interfacial Tension } \\
(\mathrm{mN} / \mathrm{m})\end{array}$ & Droplet Volume $(\mu \mathrm{L})$ & $\begin{array}{c}\text { Recommended } \\
\text { Rotational Speed } \\
\text { Interval (rpm) }\end{array}$ & $\begin{array}{c}\text { Approximate } \\
\text { Equilibration Time }\end{array}$ \\
\hline Surfactant-air-water & $10-40$ & $20-25$ & $7000-10,000$ & 30 min-a few hours \\
\hline Oil-water (with asphaltenes) & $10-40$ & $20-25$ & $7000-10,000$ & 1 h-several hours \\
\hline SOW with high tension & $2-10$ & $10-20$ & $6000-10,000$ & $20 \mathrm{~min}-2 \mathrm{~h}$ \\
\hline SOW system with low tension & $0.1-2$ & $5-10$ & $4000-6000$ & $20 \mathrm{~min}-2 \mathrm{~h}$ \\
\hline SOW system with ultralow tension & $0.0001-0.1$ & $0.5-5$ & $3000-4000$ & $1 \mathrm{~min}-1 \mathrm{~h}$ \\
\hline
\end{tabular}

${ }^{1}$ This is the recommended interval for rotational speeds according to the tension value. While oscillating, an area change below $10 \%$ is necessary to keep the rheological response linear [7].

After appropriate droplet volume, rotational speed and temperature are set, the next step is to input the oscillation rotational speed amplitude to carry out the measurement. The droplet's interface (or surface) area variation must be no more than $10 \%$ to keep the rheological response linear. In order to achieve this, an oscillation amplitude from 300 to $1000 \mathrm{rpm}$ is recommended when rotational speeds are between 3000-4000 rpm, 4000-6000 rpm or $6000-10,000 \mathrm{rpm}$ for ultralow, low, and high interfacial tensions, respectively.

Finally, the oscillation frequency $(\omega)$ is adjusted according to the measurement that will be performed. For systems where the interfacial rheological measurement will be related to emulsion stability, $\omega$ can be set at $0.1 \mathrm{~Hz}$ to match the characteristic time scale of the phenomenon [17]. In contrast, for a broader study of the system response to a frequency change, a frequency sweep can be made from $\omega=0.015$ to $0.25 \mathrm{~Hz}$. 
When a frequency sweep is made with the oscillatory spinning drop interfacial rheometer, two levels of frequency could be analyzed [7,13]:

1. At very low frequency $(0.025 \mathrm{~Hz}$ or lower), the oscillation time is quite long; hence the time is sufficient for surfactant exchanges to occur and surfactant to adsorb. Therefore, surface concentration (i.e., surface tension) gradients are very low, relaxation occurs, and Gibbs-Marangoni effects are negligible. That is probably one of the reasons why dilational modulus becomes very low.

2. At a high frequency (much higher than $0.25 \mathrm{~Hz}$ ), the oscillation time is very short. It doesn't give sufficient time for surfactant molecules to adsorb when the droplet elongates. This generates an interface that behaves as an elastic body. The dilational modulus becomes very high, reaching the limiting elasticity plateau, where the interface behaves as an "insoluble" monolayer. Among the particularities of these systems, we can mention that the external phase must be transparent or just a little opaque; otherwise, the measurement cannot be performed because the software cannot distinguish the interface in the photographic data. Usually, the external phase is transparent; hence the measurement is straightforward.

\section{The Measurement of Simple Surfactant-Oil-Water Systems with the Spinning Drop Interfacial Rheology Technique}

The interfacial tension of surfactant-oil-water systems has been known to vary according to the physicochemical formulation more than 50 years ago, whatever the changed variables, e.g., the oil nature, the brine salinity, the surfactant type, or the temperature $[1,3,27]$. The effect of temperature had been noted even before in relation to the system phase inversion [28,29]. It was basically found an almost linear relationship between the different variables at a surfactant-oil-water formulation corresponding to a minimum tension. Among them the oil alkane carbon number ACN, the brine salinity $\mathrm{S}$ (or LnS for ionic surfactants), the surfactant and cosurfactant nature, the temperature and the pressure for all types of surfactants, i.e., anionics [30], nonionics [31], cationics [32] as well as more complex ones like the extended multiblock structures [33-35]. These correlations were related to the chemical potential difference of the surfactant in the oil and water phases and expressed as a surfactant affinity difference [36]. It was expressed adimensionally as the hydrophilic-lipophilic deviation away from optimal formulation HLD [37], i.e., a linear equation with up to 5-6 variables [38]. This expression was adjusted to use the same scale in all cases and was called $\mathrm{HLD}_{\mathrm{U}}$ (U for unique) [24] or normalized HLD $\mathrm{N}_{\mathrm{N}}$ [39]. These slight changes allowed to eliminate some confusion and to return to the original pseudo-characterization of the surfactant through the named preferred ACN (so-called Nmin or PACN) in an alkane carbon number scan carried out from the 1970s [40] to last year [41]. The normalized surfactant contribution parameter $\mathrm{SCP}_{\mathrm{N}}$ in the last proposed $\mathrm{HLD}_{\mathrm{N}}$ equation $[39,42]$ is not a characteristic of the surfactant. Nevertheless, it allows to make some ranking in the hydrophilicity in the different species and calculate average mixtures' average effects. For an ionic surfactant, the optimum formulation expression is as follows:

$\mathrm{HLD}_{\mathrm{N}}=0=\mathrm{K}_{\mathrm{S}}\left(\mathrm{LnS} / \mathrm{S}_{\mathrm{ref}}\right)-\left(\mathrm{ACN}-\mathrm{ACN}_{\mathrm{ref}}\right)-\mathrm{K}_{\mathrm{T}}\left(\mathrm{T}-\mathrm{T}_{\mathrm{ref}}\right)-\mathrm{K}_{\mathrm{P}}\left(\mathrm{P}-\mathrm{P}_{\mathrm{ref}}\right)+\mathrm{SCP} \mathrm{P}_{\mathrm{N}}-\mathrm{SCP}_{\mathrm{Nref}}$

where the usual references are, for the $S_{\text {ref }}=1 \mathrm{wt} \% \mathrm{NaCl}$, for the oil $\mathrm{ACN}_{\text {ref }}=0$, that is not a very logical alkane carbon number but approximately corresponds to benzene, $\mathrm{T}_{\text {ref }}=0{ }^{\circ} \mathrm{C}$ and $\mathrm{P}_{\text {ref }}=0 \mathrm{~atm}$. The $\mathrm{SCP}_{\text {ref }}$ is arbitrarily taken as zero all the time, even if the main reason is to eliminate it from the equation because its physicochemical meaning is not well understood. The main use of the HLD equation is that it allows predicting properties of surfactant-oil-water systems with some accuracy for both equilibrated and stirred systems like emulsions and foams [43-46]. In particular, as far as EOR or dehydration are concerned, for the out of optimum cases $\left(\operatorname{HLD}_{\mathrm{N}}<<0\right.$ or $\left.\operatorname{HLD}_{\mathrm{N}}>>0\right)[39,42]$, high interfacial tensions and high emulsion stability are usual. However, at $\operatorname{HLD}_{\mathrm{N}}=0$ ultralow 
tension, very unstable emulsions and foams and very low $E^{\prime}$ and interfacial viscosity values are attained $[17,18]$.

An issue that must be considered in SOW systems at low/ultralow interfacial tension is the droplet volume placed inside the capillary. The interfacial tension generally decreases with time due to the increasing surfactant adsorption at the interface. A lower tension generates more interfacial area and thus elongates the drop, which is why the drop volume in systems with ultralow interfacial tension must be very low (typically $<1 \mu \mathrm{L}$ ).

Several SOW systems were reported in previous works, from very simple ones with conventional surfactants to more complex ones with extended surfactants, alcohol cosurfactant, different salts, and petroleum cuts [17-19,47]. Two trends were discovered for the first time:

1. The attainment of a very low elastic modulus $E^{\prime}$ at optimum formulation (Figure 3a) has been explained by the occurrence of very fast surfactant exchanges between the bulk and the interface at $\mathrm{HLD}_{\mathrm{N}}=0[17,23]$. This generates very low interfacial tension gradients and the disappearance of the Gibbs-Marangoni effect.

2. The systematic occurrence of a minimum phase angle at $\mathrm{HLD}_{\mathrm{N}}=0$ (Figure $3 \mathrm{~b}$ ). This is probably due to the formation of non-wetting microemulsion lenses around the droplet $[10,19,48-50]$, which provides a more elastic response to the interface. More performant $\mathrm{SOW}$ systems, i.e., higher solubilization, seem to relate to a lower phase angle $[19,21]$.
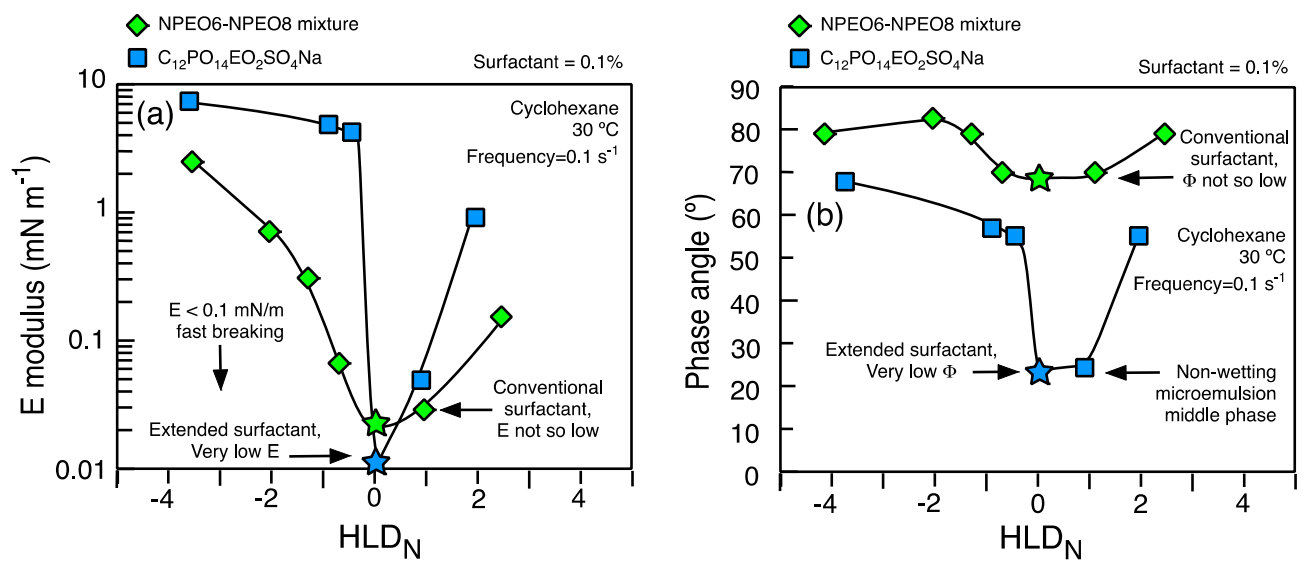

Figure 3. (a) Dilational elasticity and (b) phase angle for the system cyclohexane/surfactant $0.1 \% /$ brine. Nonionic surfactant: NEOP6-NPEO8 mixture (EON scan) and anionic extended surfactant: $\mathrm{C}_{12} \mathrm{PO}_{14} \mathrm{EO}_{2} \mathrm{SO}_{4} \mathrm{Na}$ (salinity scan) were used.

According to the system's performance, typical values of $E$ at optimum formulation range from 0.01 to $0.1 \mathrm{mN} / \mathrm{m}$. Phase angle values at $\mathrm{HLD}=0$ are minimum and vary according to the kind of surfactant present in the system. This minimum value could be related to a transient microemulsion middle phase that can be formed at the droplet interface. More extensive details about these systems, with anionic, nonionic and extended surfactants, have been reported recently [17-19].

Equilibration times can change according to the vicinity of optimum formulation and surfactant concentration. At $\mathrm{HLD}_{\mathrm{N}}=0$ and high surfactant concentration (e.g., higher than $0.5 \mathrm{wt} \%$ ), equilibrium is reached almost instantly. At optimum formulation, the diffusive surfactant exchanges with the interface are very fast and adsorption occurs almost instantly $[17,23]$.

The measurement of SOW systems at optimum formulation seems to relate interfacial dilational rheological properties to the $\mathrm{c} \mu \mathrm{c}$. Figure 4 shows a typical interfacial storage modulus ( $\left.E^{\prime}\right)$ measurement of a simple SOW system at optimum formulation, where ultralow interfacial tensions are attained [17]. Two systems are depicted: one very simple with SDBS (sodium dodecylbenzene sulfonate), and another slightly more complex by 
adding sec-butanol as co-surfactant. The maximum in the modulus at low surfactant concentration can be explained by two phenomena: (i) molecular rearrangements and (ii) an increase in surfactant exchanges at higher concentrations. Molecular rearrangement generates a higher modulus because of higher molecular interactions. Then at higher surfactant concentration, surfactant exchanges between the bulk and the interface increase, making the modulus lower [10]. At high surfactant concentration, when $\mathrm{c} \mu \mathrm{c}$ is reached, $\mathrm{E}^{\prime}$ decreases to almost zero values; this is occurring due to the acceleration of surfactant exchanges between the bulk and the interface $[17,23]$.

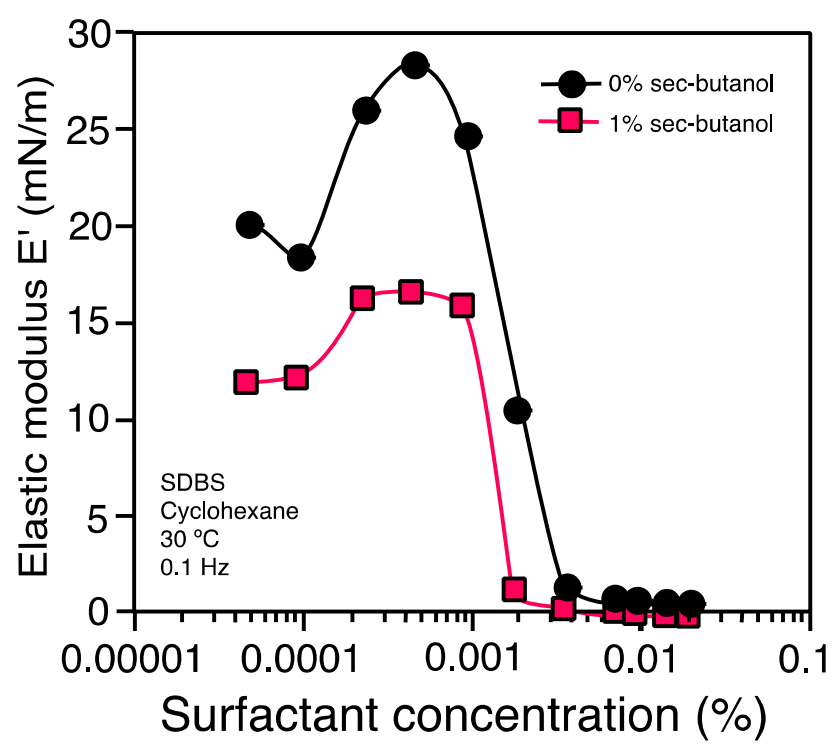

Figure 4. Storage modulus' variation as a function of surfactant concentration in the SDBScyclohexane-brine system, with and without sec-butanol as co-surfactant. Frequency $=0.1 \mathrm{~Hz}$. $\mathrm{T}=30^{\circ} \mathrm{C}$. SDBS concentration $0.02 \%$.

\section{The Measurement of Complex Crude Oil/Brine Systems (with Asphaltenes)}

Asphaltenes are defined as species from crude oil, which are soluble in aromatic solvents like toluene or xylene, but insoluble in n-pentane or n-heptane. Asphaltenes are polycyclic molecules composed of several aromatic rings surrounded by hydrocarbon chains. Its molecular weight ranges between 500 and $1000 \mathrm{~g} / \mathrm{mol}$, and can form nanoaggregates and later larger clusters [51,52].

Asphaltenes are known to contain polar groups (ester, ether, carbonyl) and acidic and alkaline groups (carboxylic and pyridine) that can be ionized over a certain $\mathrm{pH}$ range. Resins are molecules defined as soluble in light alkanes (pentane, hexane, or heptane) but insoluble in liquid propane. They consist primarily of naphthenic and aromatic hydrocarbons, generally aromatic ring systems with alicyclic chains, being effective molecules as asphaltenes dispersants [53]. In contrast, naphthenic acids are natural carboxylic acids present in petroleum, which can ionize at low and high $\mathrm{pH}$. Examples of the molecular structure of asphaltene and resins are shown in Figure 5 [54].

The polycyclic aromatic structure inside an asphaltene molecule is the main site of intermolecular attraction due to London dispersion forces and dipoles at limited sites. At the same time, the molecular exterior, with alkyl substituents, produces steric repulsion. According to the Yen-Mullins model [55,56], asphaltenes molecules form nanoaggregates at sufficiently high concentrations. Each of these aggregates is formed on average by 6-7 molecules of asphaltene and at the same time can form "clusters," i.e., larger aggregates, which are conformed by an average of 8-10 nanoaggregates $[57,58]$. The critical nanoaggregation concentration (CNAC) has been approximated at 50-200 ppm of asphaltenes in the toluene solvent, while the critical clustering concentration (CCC) has been estimated to be close to 2000-5000 ppm [59-61]. 


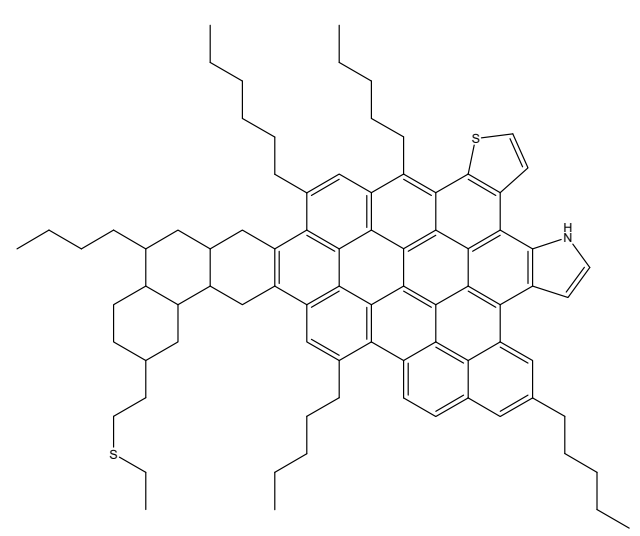

(a)

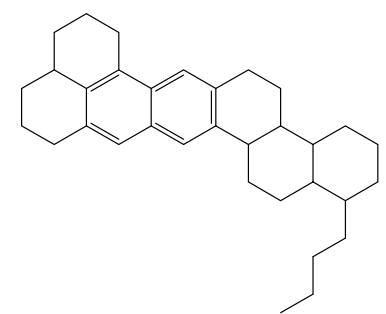

(b)

Figure 5. Examples of molecular structures of asphaltene (a) and resin (b).

Asphaltenes closely adsorbed at the interface or next to it can present lateral interactions, significantly increasing dilational interfacial elasticity and viscosity. This is generally due to the formation of a rigid, viscoelastic layer with high mechanical resistance to flow in the film [10,62]. The actual case is somehow complex because this film is composed of natural surfactants from petroleum, such as asphaltenes, resins, and naphthenic acids, as well as particles of inorganic solids or waxes present in the system [52,56,62-64].

When the asphaltenes aggregation process occurs, a subsequent adsorption/precipitation at the interface follows, generating a viscoelastic multilayer interfacial film. Figure 6 depicts this phenomenon schematically. Two levels of aggregation have been described in the literature [55]. At low asphaltene concentration (usually near $100 \mathrm{ppm}[65,66])$ the formation of nanocolloids occur, which have been labeled "nanoaggregates" according to the Yen-Mullins model [67]. These aggregates adsorb at the interface as a 2D more or less "flat" film [59], being the more polar ones the most interfacially active [68]. This rigid interface has a high dilational modulus because the high surface energy provides a significant driving force to restore the deformation [10]. The available interface saturation with these species is reached by increasing the concentration of asphaltenes. This is why the adsorption of aggregates no longer occurs in two dimensions but as a three-dimensional "cluster" or 3D fractal aggregate arrangement (approximately at 1000-2000 ppm) [69], which increases, even more, the stability of water-in-crude oil emulsions [59]. This second stage generates a more lipophilic aggregate, minimizing surface energy to avoid asphaltene precipitation $[66,68]$. Resins and polar organic acids, being molecules smaller than asphaltenes, can compete for the interfacial space during relaxation after the deformation of the drops. These substances being interfacially active may influence interfacial tension and, therefore, the interfacial rheological behavior $[54,62,70]$.

Water-in-crude oil emulsions stabilized by natural surfactants are produced in systems far from the optimum formulation at $\mathrm{HLD}_{\mathrm{N}}>0$. Their high stability is caused by the formation of a viscoelastic interfacial film of asphaltenes aggregates similar to a gel $[26,51,59,62]$. This "skin" can be formed a few hours after the emulsification, providing very high stability to these encapsulated drop emulsions. This is why the phenomena of destabilization of water-in-crude oil emulsions using demulsifiers have been studied for more than 50 years, being still the focus of many investigations [20,60,72,73].

Dilution of crude oil in a solvent that does not precipitate asphaltene has allowed studying the interfacial rheological behavior of these systems. Toluene or cyclohexane are used in most cases, and consequently, a common phenomenology has been found $[59,74]$. Also, the dispersion of asphaltenes extracted from crude oil can be performed with appropriate mixtures of these solvents, sometimes including heptane. Both the dynamic and equilibrium behaviors of interfacial tension and the dilational rheology of these systems have been studied in the past 20 years [51,75]. In addition, the effect of the asphaltene content, asphaltene type and nature of the oil phase in dilational rheology is 
currently widely known, although still being the center of extensive research. A summary of the works reporting these properties is shown in Table 2.

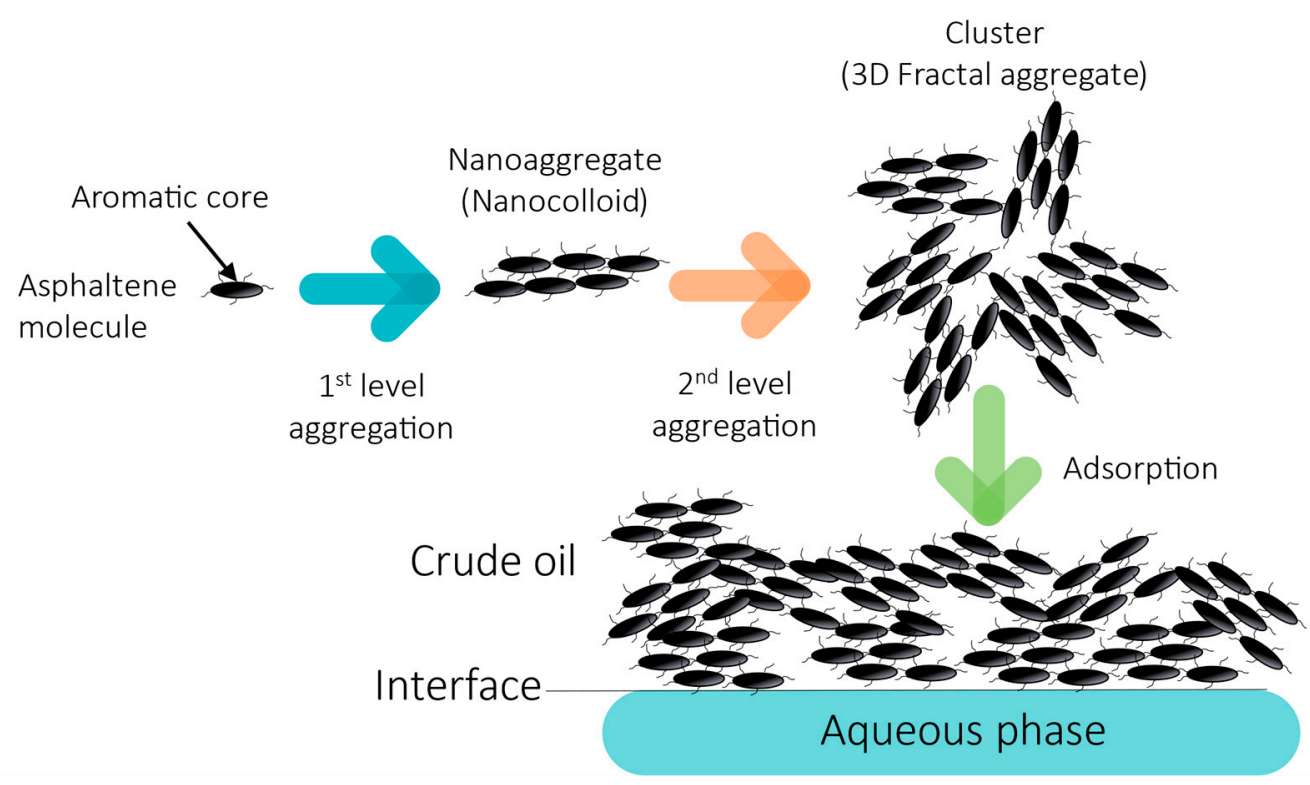

Figure 6. Schematic representation of the aggregation of individual asphaltene molecules in primary asphaltene aggregates. This is followed by formation of larger aggregates, adsorption at the oil-water interface and the formation of a network, generating a rigid viscoelastic film $[55,57,58,71]$.

Table 2. Interfacial rheological properties of water-crude oil systems.

\begin{tabular}{|c|c|c|c|}
\hline Variable & Property & Description & Reference \\
\hline \multirow[t]{2}{*}{ Time } & $\begin{array}{l}\text { Dynamic interfacial } \\
\text { tension }\end{array}$ & $\begin{array}{l}\text { Reduction of dynamic } \\
\text { interfacial tension over } \\
\text { time until equilibrium }\end{array}$ & {$[7,14,59,76-79]$} \\
\hline & $\begin{array}{l}\text { Dynamic interfacial } \\
\text { modulus }\end{array}$ & $\begin{array}{l}\text { Increase in the modulus } \\
\text { over time }\end{array}$ & {$[7,14,77,80-85]$} \\
\hline \multirow{2}{*}{$\begin{array}{l}\text { Asphaltene } \\
\text { concentration }\end{array}$} & Interfacial tension & $\begin{array}{l}\text { Reduction of interfacial } \\
\text { tension with the } \\
\text { concentration of } \\
\text { asphaltenes up to } \\
\text { saturation of the interface }\end{array}$ & {$[7,59,78,86]$} \\
\hline & Dilational modulus & $\begin{array}{l}\text { Increase of dilational } \\
\text { modulus with the } \\
\text { asphaltene concentration } \\
\text { up to a maximum } \\
\text { between } 1000 \text { and } 10,000 \\
\text { ppm of asphaltenes }\end{array}$ & {$[7,16,59,82,87-89]$} \\
\hline Oil phase nature & Elastic modulus E' & $\begin{array}{l}E^{\prime} \text { increase when the oil } \\
\text { phase is less polar }\end{array}$ & {$[7,16,78,88]$} \\
\hline
\end{tabular}

The oscillating pendant drop has been the most widely used method for measuring dilational interfacial rheology properties at the water/crude oil interface. We present here measurements and a description of the interfacial phenomena in asphaltene-laden interfaces and the interfacial rheology behavior with the oscillating spinning drop apparatus.

\subsection{Dynamic Interfacial Tension}

Asphaltenes are substances that tend to decrease interfacial tension in water-crude oil systems due to their high interfacial activity when compared with other components 
found in petroleum [59]. The dynamic interfacial tension in water-crude oil systems decreases gradually due to the continuous adsorption of surfactant molecules at the interface, presenting long adsorption times [90-92], much higher than those estimated by diffusion phenomena. The diffusion time is estimated as:

$$
\mathrm{t} \sim \Gamma^{2} /\left(6 \mathrm{DC} C^{2}\right)
$$

where $\mathrm{D}$ is the diffusion coefficient, $\Gamma$ is the concentration at the interface (mass of surfactant $m$ divided by surface area $\mathrm{A}$ ), and $\mathrm{C}$ is the concentration in liquid volume. The adsorption time for asphaltenes is in general long. Therefore, the reorientation of the molecules at the interface has been proposed to be similar to proteins [76].

The dynamic interfacial tension in water-crude oil systems decreases over time until it reaches equilibrium [59,77], as depicted in Figure 7. This behavior is not obvious in some systems since when asphaltenes species are quite large, the interface lasts a long time without reaching equilibrium. This probably occurs due to the rearrangement of asphaltenes molecules at the interface after being adsorbed as aggregates $[14,59,84]$.

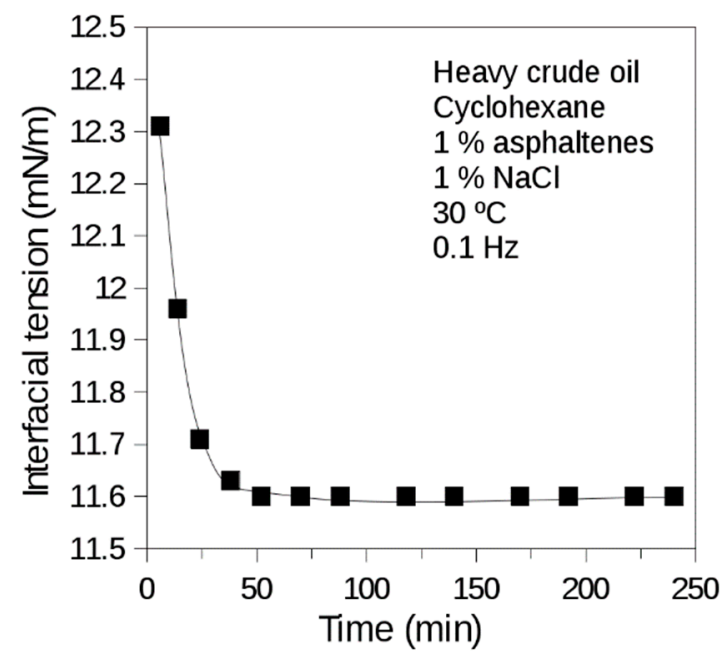

Figure 7. Dynamic interfacial tension of brine $(1 \% \mathrm{NaCl})$-heavy crude oil diluted in cyclohexane $(1 \%$ asphaltenes) system. Heavy Venezuelan crude oil of $8^{\circ}$ API with high asphaltene content (17 wt $\left.\%\right)$ diluted in cyclohexane. $\mathrm{T}=30^{\circ} \mathrm{C}$. Measurement made with the oscillating spinning drop equipment.

The dynamic interfacial tension behavior can be related to diffusion, adsorption, reorganization, and reorientation of asphaltene molecules at the interface. The mathematical models of adsorption used to describe the variation of interfacial tension as a function of time indicate two stages. A time $t_{1}$ first stage is related to diffusion and adsorption of molecules at the interface. The second time $t_{2}$ has been related to the reorganization of the irreversibly adsorbed molecules as aggregates $[76,78,79]$.

\subsection{Dynamic Dilational Modulus}

In air-crude oil [91] and water-crude oil interfaces [14,82,83], the dilational and shear interfacial moduli change more substantially and longer than the interfacial tension. This is essentially due to the reorganization of asphaltenes molecules already present at the interface. The dilational modulus of asphaltenes diluted in toluene or toluene-heptane mixtures continuously increases in times greater than $20 \mathrm{~h}$. This occurs due to the continuous reorganization of asphaltenes molecules, which conform the interfacial film $[14,77,84,85,87]$.

Probably, only a part of the asphaltenes present in the oil phase is adsorbed, depending on their molecular structure, solvent characteristics, medium $\mathrm{pH}$, etc. As the asphaltenes reorganization occurs, the amount of adsorbed molecules is more significant than that calculated with the diffusion Equation (1). Visual observation of "skins" at the interface after compression of the water-crude oil interface has been related to high shear interfacial 
viscosities and dilational moduli that grow slowly over time. This maturation of the interface is one of the most important causes of the high stability of water-in-crude oil emulsions $[14,54]$, forming highly dissipative interfaces that can be correctly described by the Boussinesq-Scriven model [70].

Figure 8 presents the variation of dilational interfacial rheology (represented by the elastic modulus) over time. This is due to the aging and reorganization of the interface [14]. The variation of dilational modulus data with time can be modeled through a biexponential equation with two times $\tau$, similar to the one proposed by Fan et al. [78]. The shorter relaxation times $\tau_{1}$ correspond to diffusion of the asphaltenes, from the bulk to the interface. The longer time $\tau_{2}$ is related to the rearrangement of the asphaltene molecules at the interface to form the interface film [85].

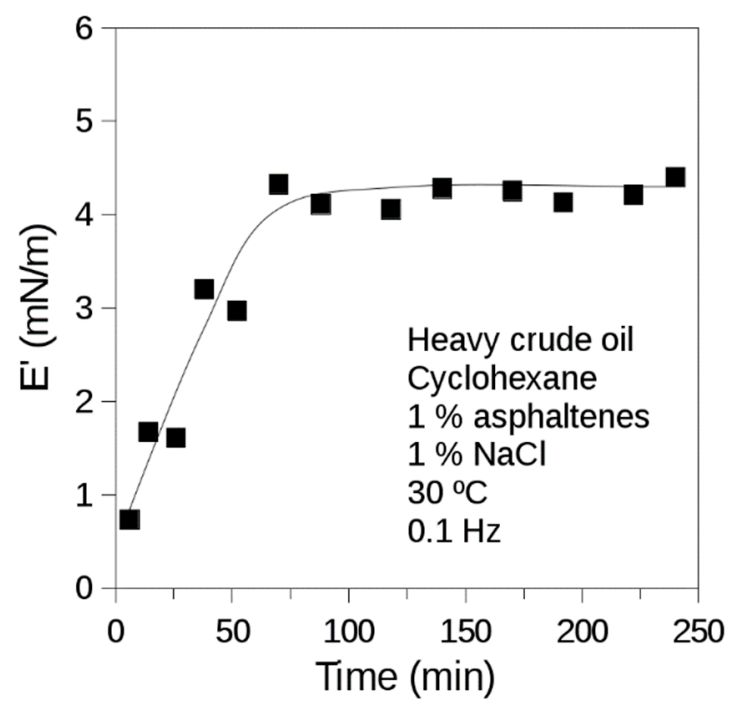

Figure 8. Dynamic elastic modulus of a brine $(1 \% \mathrm{NaCl})$-heavy crude oil diluted in cyclohexane (1\% asphaltenes). Heavy Venezuelan crude oil of $8^{\circ}$ API with high asphaltene content (17 wt $\left.\%\right)$ diluted in cyclohexane. $\mathrm{T}=30^{\circ} \mathrm{C}$. Measurement made with the oscillating spinning drop equipment. Frequency $0.1 \mathrm{~s}^{-1}$.

Dynamic processes that occur during adsorption, formation and reorganization of the film are also a function of the pre-equilibration time of the system. By increasing the pre-equilibration time, the modulus increases and the phase angle decreases when there are large molecules. In contrast, in smaller fractions, a maximum in the modulus is observed, both phenomena related to higher stability of the emulsions [80].

\subsection{Effect of Asphaltene Concentration on Interfacial Tension and Moduli}

\subsubsection{Interfacial Tension at Equilibrium}

Interfacial tension decreases when asphaltene concentration is increased, presenting a breakpoint related to the reorganization of the interfacial film and forming a 3D asphaltenes structure $[59,78,86]$. Figure 9 shows the breaking point of the interfacial tension vs. concentration of asphaltenes data, which occurs at about $20 \mathrm{~g} / \mathrm{L}(20,000 \mathrm{ppm})$ in a cyclohexane solvent $[7,59]$. 


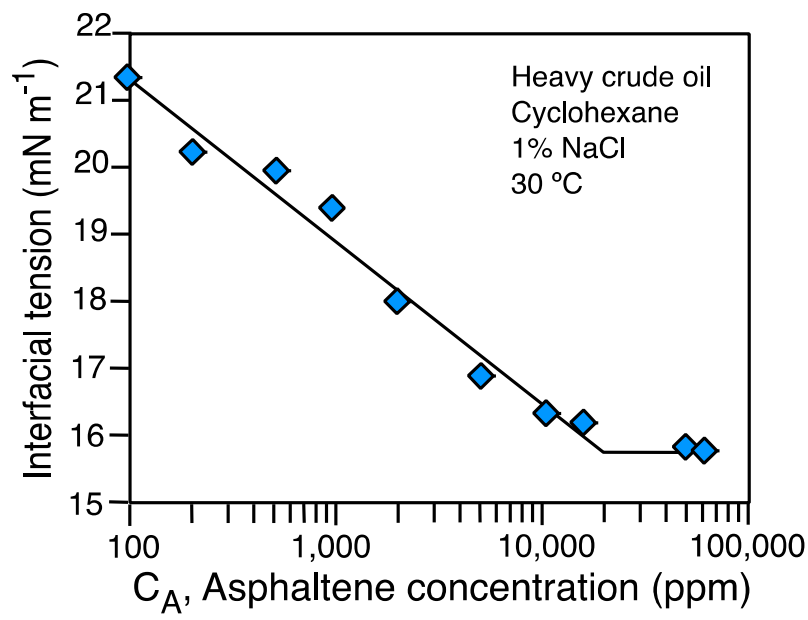

Figure 9. Interfacial tension vs. asphaltene concentration for a brine ( $1 \% \mathrm{NaCl})$-heavy crude oil diluted in cyclohexane system. Heavy Venezuelan crude oil of $8^{\circ}$ API diluted in cyclohexane. $\mathrm{T}=30^{\circ} \mathrm{C}$. Measurement made with the oscillating spinning drop equipment.

\subsubsection{Dilational Modulus at Equilibrium}

The dilational and shear interfacial modulus presents a maximum that is usually found at concentrations of 1000 to $10,000 \mathrm{ppm}$ of asphaltenes in toluene or cyclohexane [7,59,82,87-89,93]. This phenomenon is shown in Figure 10: at low asphaltenes concentrations, the adsorption is in the form of a reversible molecular monolayer [87], and at higher concentrations, a monolayer of aggregates is formed, which was tested with neutron diffusion measurements [59]. At even higher concentrations, larger 3D aggregates form, which does not contribute to the elastic interface formation, leading to a decreased dilational modulus.
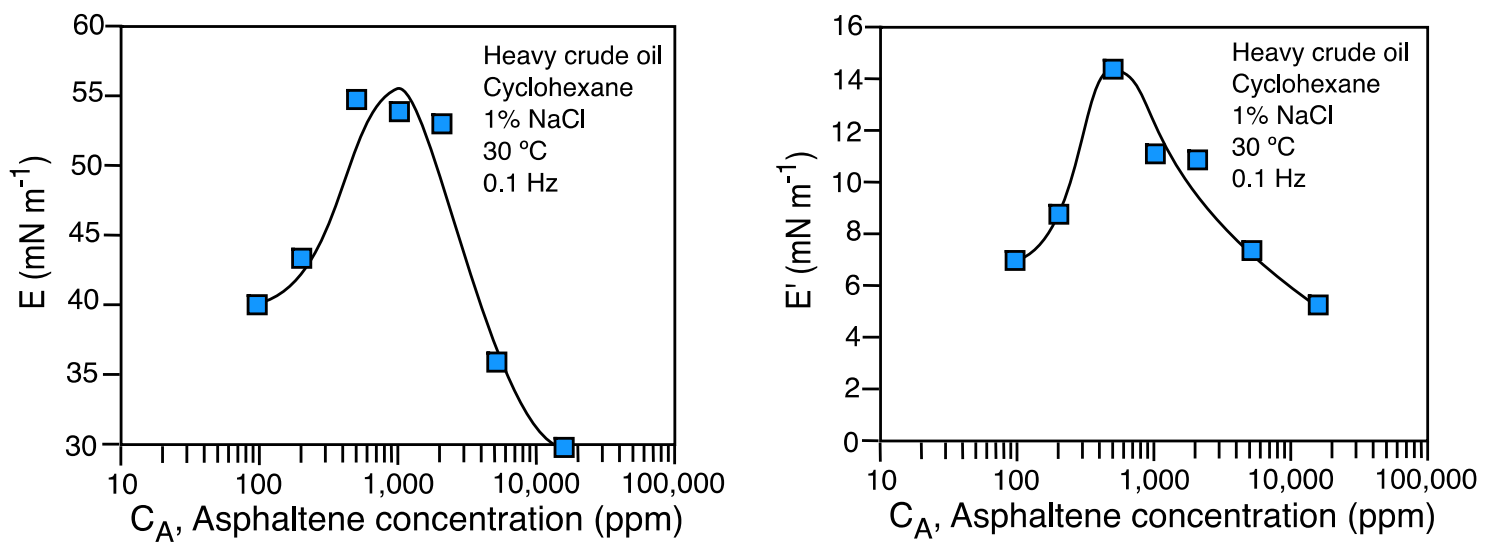

Figure 10. (Left): Relationship between dilational modulus $E$ and asphaltenes concentration. (Right). Elastic modulus $E^{\prime}$ vs. concentration of asphaltenes. Both systems are heavy Venezuelan crude oil diluted in cyclohexane-brine $(1 \% \mathrm{NaCl})$. $\mathrm{T}=30^{\circ} \mathrm{C}$. Measurement made with the oscillating spinning drop equipment. Frequency $=0.1 \mathrm{~Hz}$.

The influence of the increase of the amount of asphaltenes on the modulus is not evident. At very high asphaltene content, larger aggregates are formed, for which E can decrease above a certain level of aggregation [7,82], as shown in Figure 10. The presence of this rigid film formed by multiple layers of asphaltenes aggregates is the most critical cause of water-in-crude oil emulsion's high stability. The adsorption of asphaltenes becomes thus irreversible. Therefore, this phenomenon cannot be described by the Lucassen and Van den Temple model of diffusion at the interface. Hence, it can be explained more accurately with models similar to protein adsorption [76,82]. The evolution of the dilational modulus due to the reorganization of the interfacial film requires a long time. The maximum modulus 
E also increases over time, as shown in previous research [88]. A relationship between the dilational storage modulus and the stability of water-in-crude oil emulsions has been found $[7,94]$.

\subsection{Asphaltene Polarity and Diluting Oil Phase Type}

Asphaltenes possess two characteristics that define their physicochemical behavior when considered as natural surfactants, i.e., their polarity and the size of the molecules. A known phenomenology has been reported for these systems: (i) asphaltenes with a greater polarity form well-consolidated films, generating higher shear and dilational moduli than those formed by less polar asphaltenes [83], and (ii) the higher molecular weight asphaltenes create more rigid interface films since aromatic compounds with large condensed rings are more significant in the formation and rigidity of the film than the smaller molecules [89]. The modulus of the smaller fractions increases faster but are of lower value, which is related to the diffusion time and reorganization at the interface $[14,80,89]$. Therefore, more polar and higher molecular weight asphaltene molecules will form an interfacial film of higher modulus and interfacial viscosity that generates greater stability in the emulsions formed.

Asphaltenes diluted in solvents such as cyclohexane or heptol (heptane/toluene mixtures) show a greater presence of larger aggregates at the interface, when compared to polar solvents such as toluene. This makes the dilational modulus larger, as depicted in Figure 11. Less polar solvents generate more rigid films with higher interfacial moduli $[7,83,95]$. This is the case when heptane is added to toluene in the solvent, thus decreasing polarity, and causing the dilational modulus to increase up to the point of precipitation of asphaltenes, after which the dilational modulus decreases. Hence, the dilational modulus is lower for appropriate asphaltene dispersants like toluene and higher for systems with cyclohexane. Therefore, emulsion stability increases in the latter case [61,74].

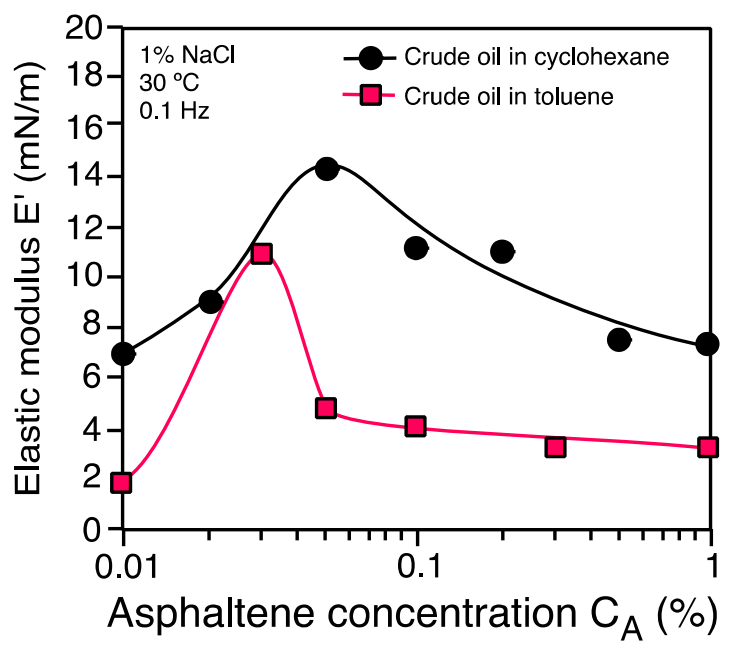

Figure 11. Elastic modulus $E^{\prime}$ variation as a function of asphaltene concentration $\left(C_{A}\right)$ in a heavy crude oil/solvent (cyclohexane or toluene)/brine $(1 \% \mathrm{NaCl})$ system. $\mathrm{T}=30^{\circ} \mathrm{C}$. Frequency $=0.1 \mathrm{~Hz}$.

In the case of heptol solvents, high heptane contents that do not reach precipitation (usually less than 50\% heptane in the heptane/toluene mixture) present a higher modulus (and greater stability of emulsions). At this point, the intermolecular bonds and hydrogen bonds between individual asphaltenes and aggregates begin to surpass the solubility of toluene, and therefore, asphaltenes precipitate [78,93]. 


\section{Dilational Interfacial Rheology in Surfactant-Crude Oil-Brine Complex Systems at Optimum Formulation}

4.1. Formulation Aspects to Attain $H L D_{N}=0$ in Water-in-Crude Oil Emulsions and Its Relationship with Emulsion Instability

Several research studies have demonstrated the role of surfactants in the destabilization of water-in-crude oil emulsions in a direct or indirect way. The first studies indicated the relationship between optimum formulation and emulsion instability [30,96-99]. Salager, in a pioneering proposal [26], explained the process of destabilizing water-in-crude oil emulsions. This report indicated that in order to destabilize petroleum emulsions, it is necessary to add demulsifying (hydrophilic) agents to reach the optimum formulation situation at $\mathrm{HLD}_{\mathrm{N}}=0$, where a minimum tension and a deep minimum in emulsion stability is occurring. This mechanism was revisited later by Goldszal and Bourrel in 2000 [100] and Rondon et al. in 2006 [74]. Recently, the attainment of optimum formulation has been related to increased performance and robustness in the minimum stability of petroleum emulsions [20,61,72,74].

In order to attain $\mathrm{HLD}_{\mathrm{N}}=0$ for water-in-crude oil emulsions breaking, a formulation scan must be performed (generally, the so-called bottle test is used in industry), varying the quantity of demulsifier added [61,72]. The selection of the best demulsifier to reach minimum stability requires attaining optimum formulation. Also, studying other factors that cause delay of the drainage of the interfacial film and oppose the deformation of the interface, avoiding drop's coalescence $[10,20,21]$.

Two levels of understanding of water-in-crude oil emulsion destabilization phenomenology are necessary to select the best demulsifier formulation. The first one is the attainment of the optimum formulation where minimum stability of emulsions occurs. This is achieved by adding the (demulsifying) surfactant to reach $H L D_{N}=0$ (as stated above). The $H L D_{N}$ concept is easily handled with known conventional surfactants. Still, its application to a system containing asphaltenes is less straightforward due to the complex behavior of asphaltenes as natural surfactants and as a polar oil segregated at the interface [60].

$\mathrm{HLD}_{\mathrm{N}}$ equation has been presented recently $[39,42]$ with a surfactant classification parameter $\left(\mathrm{SCP}_{\mathrm{N}}\right)$ that incorporates both the contribution of the demulsifier and natural surfactants (asphaltenes mainly). When anionic or nonionic surfactants are present $H_{L} D_{N}$ can be expressed as [72]:

$$
\begin{aligned}
& \mathrm{HLD}_{\mathrm{N}-\mathrm{AI}}=\mathrm{SCP}_{\mathrm{N}-\mathrm{M}}+\mathrm{k}_{\mathrm{S}} \ln \mathrm{S}-\mathrm{EACN}-\mathrm{k}_{\mathrm{aT}}(\mathrm{T}-25) \text { for anionic surfactants } \\
& \mathrm{HLD}_{\mathrm{N}-\mathrm{NI}}=\mathrm{SCP}_{\mathrm{N}-\mathrm{M}}+\mathrm{k}_{\mathrm{b}} \mathrm{S}-\mathrm{EACN}+\mathrm{k}_{\mathrm{CT}}(\mathrm{T}-25) \text { for nonionic surfactants }
\end{aligned}
$$

where $\mathrm{SCP}_{\mathrm{N}-\mathrm{M}}$ is the surfactant classification parameter of the surfactant mixture at the interface, $\mathrm{S}$ is the salinity in $\mathrm{wt} \%, \mathrm{EACN}$ is the equivalent alkane carbon number, $\mathrm{T}$ the temperature in ${ }^{\circ} \mathrm{C}$, and $\mathrm{k}_{\mathrm{S}}, \mathrm{k}_{\mathrm{b}}, \mathrm{k}, \mathrm{k}_{\mathrm{aT}}$ and $\mathrm{k}_{\mathrm{cT}}$ are positive constants that vary according to the system.

The asphaltene-demulsifier interfacial mixture can be in some cases approximated to a linear equation, which can be expressed as [20,72]:

$$
\mathrm{SCP}_{\mathrm{N}-\mathrm{M}}=\mathrm{X}_{\mathrm{A}} \mathrm{SCP}_{\mathrm{N}-\mathrm{A}}+\mathrm{X}_{\mathrm{D}} \mathrm{SCP}_{\mathrm{N}-\mathrm{D}}
$$

where $X_{A}$ and $X_{D}$ are the molar fractions of asphaltenes (A) and demulsifier (D) at the interface, and $\mathrm{SCP}_{\mathrm{N}-\mathrm{A}}$ and $\mathrm{SCP}_{\mathrm{N}-\mathrm{D}}$ are the surfactant classification parameters for asphaltenes and demulsifier, respectively.

The second requirement for water-in-crude oil emulsion breaking is to attain the minimum stability and increase the performance and robustness [101]. This can be attained by reducing the rheological parameters, particularly the dilational modulus, thus increasing the drainage rate of thin films that form between approaching emulsion drops $[10,20,26]$. This second level deals with a performance issue on how to get minimum stability which should be as low as possible, particularly by increasing the thin film drainage rate. This can be achieved by altering the minimum interfacial tension, affecting the 
Gibbs-Marangoni effect, and reducing the rheological effects by attaining a WIII system. As a consequence, a bicontinuous microemulsion forms and surfactant exchanges are considerably accelerated $[17,23]$. Therefore, Gibbs-Marangoni effects become very low and are almost negligible $[10,20]$.

A performant demulsifier to be effective must be transferred rapidly through the oil phase to the oil/water interface. This requires a formulation that increases surfactant exchanges between the bulk and the interface. Multiple reports have indicated in some way the following strategies to attain higher performance:

(a) Demulsifier molecular weight and structure: a demulsifier molecule of smaller size and having more interactions with the aqueous and oil phase (according to Winsor's $\mathrm{R}$ theory) will be transported to the interface faster and will perform maybe better [24,102,103].

(b) Driving force: the more hydrophilic surfactants go faster to the interface $[61,72,74,102]$. Hence, using a surfactant that has a lower $\mathrm{SCP}_{\mathrm{N}}$ is better. Nevertheless, $\mathrm{SCP}_{\mathrm{N}}$ should not be too negative (very hydrophilic), because in such case, it solubilizes preferentially in the aqueous phase [74].

(c) Formulation quality: at optimum formulation where a WIII microemulsion and ultralow interfacial tension are attained, the mass transfer is considerably accelerated $[17,23,104]$.

(d) The presence of cosurfactants: additives such as alcohols (sec-butanol in particular) can increase the rate of mass transfer at the interface $[17,21,105,106]$. All these phenomena are optimized to attain a high performance of the formulation $[25,73,103,107]$.

In recent reports, the occurrence of minimum dilational rheology moduli has been related to the attainment of $H_{L} D_{N}=0$ in surfactant-crude oil-brine systems [20,21]. Different systems were studied, including nonionic, anionic and extended surfactants. The phenomenology indicates some trends that are consistent no matter the type of oil or surfactant used:

1. A minimum in interfacial tension and dilational moduli is systematically attained in a formulation scan at optimum formulation. The minimum in the elastic moduli can be explained by the acceleration of surfactant exchanges between the bulk and the interface, which makes Gibbs-Marangoni effects almost negligible.

2. The phase angle also presents a minimum at $H L D_{N}=0$, which varies according to the surfactant and cosurfactant species. This has been explained by the possible formation of a microemulsion lens around the droplet due to the non-wetting behavior of the bicontinuous middle phase.

3. Concomitant minimum emulsion stability is generated at $\operatorname{HLD}_{\mathrm{N}}=0$. This has been explained by the very low elastic modulus attained due to the very fast surfactant exchanges. It could also be since almost all of the surfactant is in the microemulsion middle phase. Hence, there is not enough surfactant available in the excess oil and water phases to stabilize emulsions.

The fundamental and application aspects of this phenomenology have helped to connect the points found in previous reports that indicated the following:

i. The best performance of the demulsifier is when it is equally soluble in oil and water $[26,61,86,102,108,109]$. In this situation, the dilational elasticity of the film is very low and provides an effective emulsion breaking process [17].

ii. The interfacial activity of the demulsifier resulting in an (ultra-) low tension should be high enough to eliminate or considerably reduce interfacial tension gradients $[61,74,86,100,102,110-112]$ so that the Gibbs-Marangoni effect tends to disappear $[17,20]$.

iii. The best demulsifiers are those with a faster progression of dynamic interfacial tension $[79,102,113]$. Cosurfactants as sec-butanol can considerably increase surfactant exchanges between the bulk and the interface, making the lowering of dynamic IFT very fast $[17,21]$. 


\subsection{Formulation Scans in Surfactant-Crude Oil-Brine Systems at the Optimum Formulation}

In what follows, formulation scans will be presented that could explain the attainment of higher performance by selecting a specially tailored surfactant with a $(\mathrm{PO})_{\mathrm{n}}$ extension to increase the surfactant interactions with the oil phase in surfactant-crude oil-brine systems.

Figure 12a-f shows the interfacial tension, dilational elasticity and phase angle when a formulation scan is made in a nonionic (NPEO6 and NPEO8 mixture) and anionic extended surfactant system $\left(\mathrm{C}_{12} \mathrm{PO}_{14} \mathrm{EO}_{2} \mathrm{SO}_{4} \mathrm{Na}\right)$, when increasing asphaltene concentrations from $\mathrm{C}_{\mathrm{A}}=300$ to $1000 \mathrm{ppm}$. EON and salinity scans were used to change HLD and attain optimum formulation. The characteristics of these surfactants are shown in previous reports $[20,21]$. As outlined in the section above, a deep minimum in interfacial tension, dilational elasticity, and phase angle can be attained in systems with surfactants, crude oil and brine.
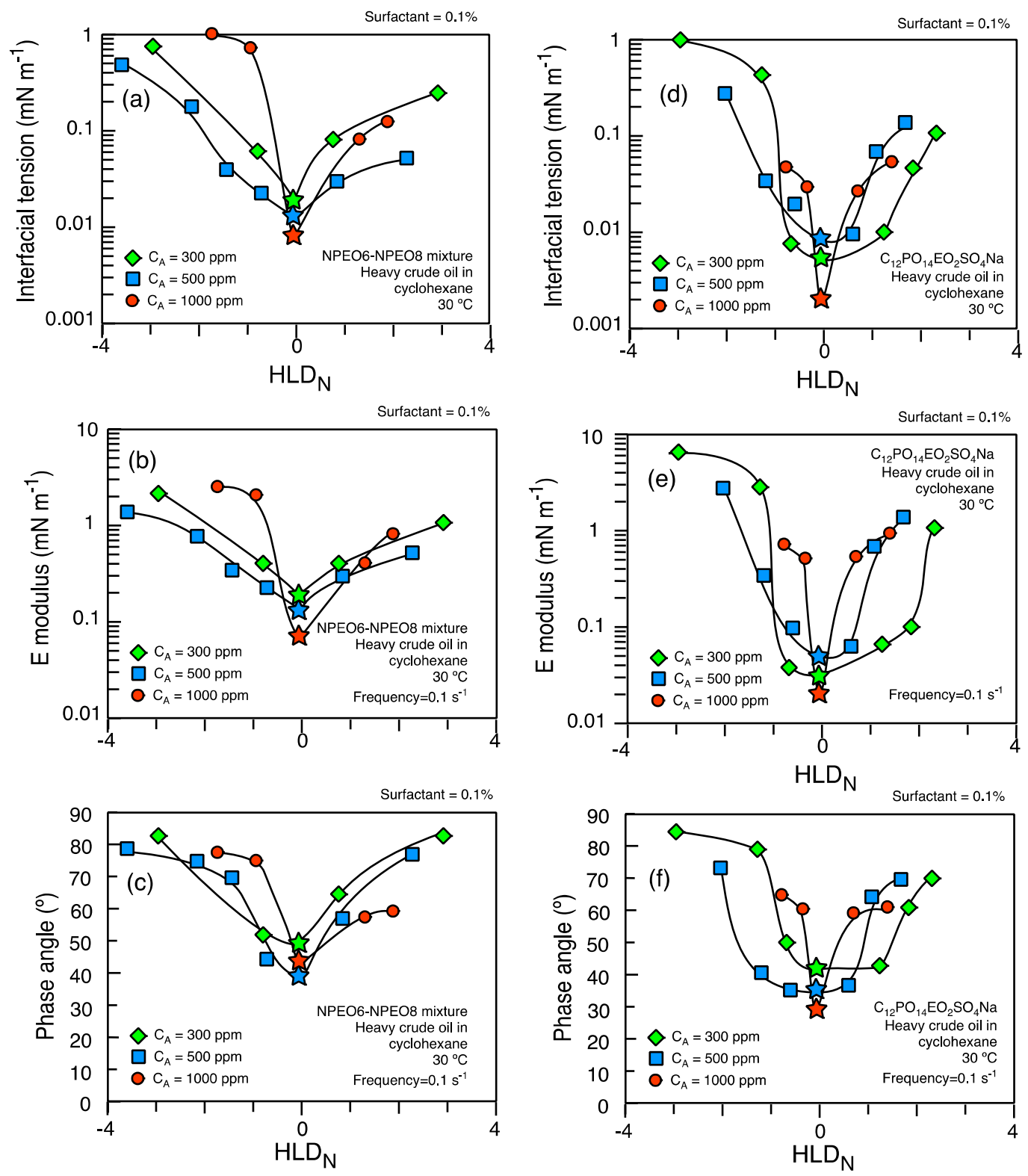

Figure 12. Interfacial tension, dilational elasticity and phase angle for a heavy crude oil diluted in cyclohexane/surfactant $0.1 \%$ /brine system. Nonionic surfactant: (a-c) NEOP6-NPEO8 mixture (EON scan), and anionic extended surfactant (salinity scan) (d-f) $\mathrm{C}_{12} \mathrm{PO}_{14} \mathrm{EO}_{2} \mathrm{SO}_{4} \mathrm{Na}$ were used. 
A better performance (lower IFT, lower E and a very low phase angle) is attained with the extended surfactant system in comparison to the nonionic conventional one. This might be explained by the occurrence of the improved interactions between the extended surfactant tail and the oil (which could include oil-like polar molecules, as asphaltenes), and surfactant and water (the first three PO seems to be hydrated as indicated in previous reports) $[20,35,103]$.

In the last 10 years, significant advancements have been achieved to understand interface properties of crude oil-surfactant-brine systems at $\mathrm{HLD}_{\mathrm{N}}=0$, where ultralow interfacial tensions and many other specific events are attained. Moreover, interfacial dilational rheology studies of surfactant-crude oil-brine interfaces with suitable equipment to work at ultralow interfacial tensions are just starting [114]. Continuing this line of research and improving the measuring methods could mean a great advancement to better understand the role of interfacial rheological properties in crude oil emulsion destabilization. This could also be of great importance to select better demulsifiers with higher performance and improved robustness.

\section{Conclusions and Perspective}

The method most used for the study of dilational interfacial rheological properties have been the oscillating pendant drop and longitudinal waves, and although new equipment has been developed (based on oscillatory Langmuir trough or microfluidics $[64,115,116])$, these techniques cannot be used in systems with low or ultralow interfacial tensions.

For more than 35 years, experimental proof of some relationship between interfacial dilational rheological properties and physicochemical formulation associated with the destabilization of water-in-crude oil emulsions with demulsifiers has been looked for without definite success.

A better understanding of interfacial properties attained with a recently developed equipment, the oscillating spinning drop interfacial rheology apparatus, is discussed in the present review. It should be noted that this is the first time that an investigation presents experimental proof of the unequivocal relationship between a deep minimum in interfacial tension, dilational interfacial rheological properties and emulsion stability in applications for crude oil dewatering at optimum formulation.

The additional work in the interfacial rheology area, which has to be done, can benefit from the present discussion on the practical way to use the oscillatory spinning drop interfacial rheometer at a formulation close to optimum. Moreover, interfacial rheology studies related to enhanced oil recovery are of utmost importance to understand the mechanisms of petroleum behavior at the interface when brines containing surfactants and polymers are present. This could also be an important advancement to study interfaces in systems with biobased polar oils or biobased surfactants [117]. This opens a large field of studies in biobased surfactants used in less environmental impact applications being researched in universities and industry.

Author Contributions: The manuscript was written through the contributions of all authors. Conceptualization, R.M., J.B., A.F. and J.-L.S.; writing—original draft preparation, R.M., A.F. and J.-L.S.; writing-review and editing, R.M. and J.-L.S.; project administration, J.B., A.F. and J.-L.S.; funding acquisition, J.B., A.F. and J.-L.S. All authors have read and agreed to the published version of the manuscript.

Funding: FIRP Laboratory and Total Energies.

Institutional Review Board Statement: Not available.

Informed Consent Statement: Not available.

Data Availability Statement: Not available.

Acknowledgments: We want to thank Dominique Langevin for enlightening discussions regarding interfacial rheology of crude oil-water interfaces. Jose Gregorio Delgado and Jose Gregorio Alvarado 
are acknowledged for their support in understanding asphaltene aggregation in water-crude oil interfaces. The researchers Jesus Fernandez, Luz Meza and Ramon Vera, are thanked for performing some of the measurements. Total Energies is thanked for funding partially the Ph.D work of the first author R.M.

Conflicts of Interest: The authors declare no conflict of interest.

\section{References}

1. Reed, R.L.; Healy, R.N. Some physicochemical aspects of microemulsion flooding: A review. In Improved Oil Recovery by Surfactant and Polymer Flooding; Academic Press: Cambridge, MA, USA, 1977; pp. 383-437.

2. Wade, W.; Morgan, J.C.; Schechter, R.S.; Jacobson, J.K.; Salager, J.-L. Interfacial tension and phase behavior of surfactant systems. Soc. Pet. Eng. J. 1978, 18, 242-252. [CrossRef]

3. Cayias, J.L.; Schechter, R.S.; Wade, W.H. Measurement of Low Interfacial Tension Via the Spinning Drop Technique. In ACS Symposium Series; American Chemical Society: Washington, DC, USA, 1975; pp. 234-247. [CrossRef]

4. Cayias, J.L.; Schechter, R.S.; Wade, W.H. Modeling crude oils for low interfacial tension. Soc. Pet. Eng. J. 1976, 16, 351-357. [CrossRef]

5. Vonnegut, B. Rotating bubble method for the determination of surface and interfacial tensions. Rev. Sci. Instrum. 1942, 13, 6-9. [CrossRef]

6. Couper, A.; Newton, R.; Nunn, C. A simple derivation of Vonnegut's equation for the determination of interfacial tension by the spinning drop technique. Colloid Polym. Sci. 1983, 261, 371-372. [CrossRef]

7. Zamora, J.M.; Marquez, R.; Forgiarini, A.M.; Langevin, D.; Salager, J.L. Interfacial rheology of low interfacial tension systems using a new oscillating spinning drop method. J. Colloid Interface Sci. 2018, 519, 27-37. [CrossRef]

8. Cash, R.; Cayias, J.L.; Fournier, G.; McAllister, D.; Shares, T.; Schechter, R.S.; Wade, W.H. The Application Of Low Interfacial Tension Scaling Rules to Binary Hydrocarbon Mixtures. J. Colloid Interface Sci. 1977, 59, 39-44. [CrossRef]

9. Chiwetelu, C.I.; Hornof, V.; Neale, G.H. The measurement of dynamic interfacial tension by photo-micropendography. J. Colloid Interface Sci. 1988, 125, 586-601. [CrossRef]

10. Langevin, D. Emulsions, Microemulsions and Foams; Springer: Cham, Switzerland, 2020; ISBN 978-3-030-55681-5.

11. Edwards, D.A.; Brenner, H.; Wasan, D.T. Interfacial Transport Processes and Rheology; Butterworths-Heinemann: Oxford, UK, 1991; ISBN 0750691859.

12. Miller, R.; Liggieri, L. Progress in Colloid and Interface Science: Interfacial Rheology; CRC Press: Boca Raton, FL, USA, 2009 ; p. 699.

13. Langevin, D. Rheology of adsorbed surfactant monolayers at fluid surfaces. Annu. Rev. Fluid Mech. 2014, 46, 47-65. [CrossRef]

14. Freer, E.; Svitova, T.; Radke, C.J. The role of Interfacial Rheology in reservoir mixed Wettability. J. Pet. Sci. Eng. 2003, 39, 137. [CrossRef]

15. Ravera, F.; Loglio, G.; Kovalchuk, V.I. Interfacial dilational rheology by oscillating bubble/drop methods. Curr. Opin. Colloid Interface Sci. 2010, 15, 217-228. [CrossRef]

16. Nguyen, D.; Balsamo, V. Emulsification of heavy oil in aqueous solutions of poly(vinyl alcohol): A method for reducing apparent viscosity of production fluids. Energy Fuels 2013, 27, 1736-1747. [CrossRef]

17. Marquez, R.; Forgiarini, A.M.; Langevin, D.; Salager, J.-L. Instability of Emulsions Made with Surfactant-Oil-Water Systems at Optimum Formulation with Ultralow Interfacial Tension. Langmuir 2018, 34, 9252-9263. [CrossRef]

18. Marquez, R.; Forgiarini, A.M.; Fernández, J.; Langevin, D.; Salager, J.-L. New Interfacial Rheology Characteristics Measured using a Spinning-Drop Rheometer at the Optimum Formulation of a Simple Surfactant-Oil-Water System. J. Surfactants Deterg. 2018, 21, 611-623. [CrossRef]

19. Marquez, R.; Antón, R.; Vejar, F.; Salager, J.L.; Forgiarini, A.M. New Interfacial Rheology Characteristics Measured Using a Spinning Drop Rheometer at the Optimum Formulation. Part 2. Surfactant-Oil-Water Systems with a High Volume of Middle-Phase Microemulsion. J. Surfactants Deterg. 2019, 22, 177-188. [CrossRef]

20. Marquez, R.; Forgiarini, A.; Langevin, D.; Salager, J.-L. Breaking of Water-In-Crude Oil Emulsions. Part 9. New Interfacial Rheology Characteristics Measured Using a Spinning Drop Rheometer at Optimum Formulation. Energy Fuels 2019, 33, 8151-8164. [CrossRef]

21. Marquez, R.; Meza, L.; Alvarado, J.G.; Bullón, J.; Langevin, D.; Forgiarini, A.M.; Salager, J.-L. Interfacial Rheology Measured with a Spinning Drop Interfacial Rheometer: Particularities in More Realistic Surfactant-Oil-Water Systems Close to Optimum Formulation at HLDN = 0. J. Surfactants Deterg. 2021, 24, 587-601. [CrossRef]

22. Slattery, J.C.; Chen, J.D.; Thomas, C.P.; Fleming, P.D. Spinning drop interfacial viscometer. J. Colloid Interface Sci. 1980, 73, 483-499. [CrossRef]

23. Fillous, L.; Cárdenas, A.; Rouvière, J.; Salager, J.-L. Interfacial Mass Transfer versus Formulation in Multiple Phase Anionic Surfactant-Oil-Water Systems. J. Surfactants Deterg. 1999, 2, 303-307. [CrossRef]

24. Salager, J.-L.; Forgiarini, A.M.; Bullón, J. How to attain ultralow interfacial tension and three-phase behavior with surfactant formulation for enhanced oil recovery: A review. Part 1. Optimum formulation for simple surfactant-oil-water ternary systems. J. Surfactants Deterg. 2013, 16, 449-472. [CrossRef] 
25. Salager, J.-L.; Forgiarini, A.M.; Márquez, L.; Manchego, L.; Bullón, J.; Marquez, L.; Manchego, L.; Bullon, J. How to Attain an Ultralow Interfacial Tension and a Three-Phase Behavior with a Surfactant Formulation for Enhanced Oil Recovery: A Review. Part 2. Performance Improvement Trends from Winsor's Premise to Currently Proposed Inter- and Intra-Molecular Mixtures. J. Surfactants Deterg. 2013, 16, 631-663. [CrossRef]

26. Salager, J.-L. Fundamental basis for the action of a chemical dehydrant. Influence of the physical and chemical formulation on the stability of an emulsion. Int. Chem. Eng. 1990, 30, 103-116.

27. Cash, R.L.; Cayias, J.L.; Fournier, G.R.; Jacobson, J.K.; LeGear, C.A.; Schares, T.; Schechter, R.S.; Wade, W.H. Low interfacial tension variables. In Proceedings of the Detergents in the Changing Scene; American Oil Chemists' Society: Urbana, IL, USA, 1975.

28. Shinoda, K.; Arai, H. The effect of phase volume on the phase inversion temperature of emulsions stabilized with nonionic surfactants. J. Colloid Interface Sci. 1967, 25, 429-431. [CrossRef]

29. Shinoda, K.; Saito, H. The effect of temperature on the phase equilibria and the types of dispersions of the ternary system composed of water, cyclohexane, and nonionic surfactant. J. Colloid Interface Sci. 1968, 26, 70-74. [CrossRef]

30. Salager, J.-L.; Morgan, J.C.; Schechter, R.S.; Wade, W.H.; Vasquez, E. Optimum formulation of surfactant/water/oil systems for minimum interfacial tension or phase behavior. Soc. Pet. Eng. J. 1979, 19, 107-115. [CrossRef]

31. Bourrel, M.; Salager, J.L.; Schechter, R.S.; Wade, W.H. A correlation for phase behavior of nonionic surfactants. J. Colloid Interface Sci. 1980, 75, 451-461. [CrossRef]

32. Antón, R.E.; Garcés, N.; Yajure, A. A correlation for three-phase behavior of cationic surfactant-oil-water systems. J. Dispers. Sci. Technol. 1997, 18, 539-555. [CrossRef]

33. Miñana-Perez, M.; Graciaa, A.; Lachaise, J.; Salager, J.-L. Solubilization of polar oils with extended surfactants. Colloids Surfaces A Physicochem. Eng. Asp. 1995, 100, 217-224. [CrossRef]

34. Miñana-Perez, M.; Graciaa, A.; Lachaise, J.; Salager, J.-L. Solubilization of polar oils in microemulsion systems. Trends Colloid Interface Sci. IX 1995, 98, 177-179. [CrossRef]

35. Salager, J.-L.; Forgiarini, A.; Marquez, R. Extended Surfactants Including an Alkoxylated Central Part Intermediate Producing a Gradual Polarity Transition-A Review of the Properties Used in Applications Such as Enhanced Oil Recovery and Polar Oil Solubilization in Microemulsions. J. Surfactants Deterg. 2019, 22, 935-972. [CrossRef]

36. Salager, J.-L.; Anton, R.E. Ionic Microemulsions. In Handbook of Microemulsion Science and Technology; Kumar, P., Mittal, K., Eds.; Marcel Dekker: New York, NY, USA, 1999; pp. 247-280.

37. Salager, J.-L.; Marquez, N.; Graciaa, A.; Lachaise, J. Partitioning of ethoxylated octylphenol surfactants in microemulsion-oil-water systems: Influence of temperature and relation between partitioning coefficient and physicochemical formulation. Langmuir 2000, 16, 5534-5539. [CrossRef]

38. Salager, J.-L.; Antón, R.E.; Forgiarini, A.; Márquez, L. Formulation of Microemulsions. In Microemulsions: Background, New Concepts, Applications, Perspectives, Stubenrauch Ed.; Wiley: Hoboken, NJ, USA, 2009; pp. 84-121, ISBN 9781444305524.

39. Salager, J.-L.; Antón, R.E.; Bullón, J.; Forgiarini, A.; Marquez, R. How to Use the Normalized Hydrophilic-Lipophilic Deviation (HLDN) Concept for the Formulation of Equilibrated and Emulsified Surfactant-Oil-Water Systems for Cosmetics and Pharmaceutical Products. Cosmetics 2020, 7, 57. [CrossRef]

40. Doe, P.; El-Emary, M.; Wade, W.; Schecter, R. The Influence of Surfactant Structure on Low Interfacial Tensions. In Chemistry of Oil Recovery; ACS Symposium Series; American Chemical Society: Washington, DC, USA, 1979; Volume 91, pp. 2-17, ISBN 9780841204775.

41. Aubry, J.M.; Ontiveros, J.F.; Salager, J.-L.; Nardello-Rataj, V. Use of the normalized hydrophilic-lipophilic-deviation (HLDN) equation for determining the equivalent alkane carbon number (EACN) of oils and the preferred alkane carbon number (PACN) of nonionic surfactants by the fish-tail method (FTM). Adv. Colloid Interface Sci. 2020, 276, 102099. [CrossRef] [PubMed]

42. Salager, J.-L. A normalized Hydrophilic-Lipophilic Deviation expression HLDN is necessary to avoid confusions close to the optimum formulation of Surfactant-Oil-Water systems. J. Surfactants Deterg. 2021, 24, 731-748. [CrossRef]

43. Salager, J.-L.; Bullón, J.; Pizzino, A.; Rondón-González, M.; Tolosa, L.; Somasundaran, P. Emulsion formulation engineering for the practitioner. In Encyclopedia of Surface and Colloid Science; Somasundaran, P., Ed.; Taylor \& Francis: New York, NY, USA, 2010; Volume 1, pp. 1-6.

44. Salager, J.-L. Emulsion Phase Inversion Phenomena. In Emulsions and Emulsion Stability; Sjoblom, J., Ed.; CRC Publishing: Boca Raton, FL, USA, 2006; p. 185.

45. Antón, R.E.; Andérez, J.M.; Bracho, C.; Vejar, F.; Salager, J.-L. Practical Surfactant Mixing Rules Based on the Attainment of Microemulsion-Oil-Water Three-Phase Behavior Systems. Adv. Polym. Sci. 2008, 218, 83. [CrossRef]

46. Salager, J.-L.; Antón, R.E.; Anderez, J.M.; Aubry, J.-M. Formulation des micro-émulsions par la méthode HLD. Tech. l'Ingénieur 2001, 157, 1-16.

47. Vera, R.E.; Salazar-Rodríguez, F.; Marquez, R.; Forgiarini, A.M. How the Influence of Different Salts on Interfacial Properties of Surfactant-Oil-Water Systems at Optimum Formulation Matches the Hofmeister Series Ranking. J. Surfactants Deterg. 2020, 23, 603-615. [CrossRef]

48. Kahlweit, M.; Strey, R.; Busse, G. Microemulsions: A qualitative thermodynamic approach. J. Phys. Chem. 1990, 94, 3881-3894. [CrossRef]

49. Langevin, D.; Meunier, J. Interfacial tension: Theory and experiment. In Micelles, Membranes, Microemulsions, and Monolayers; Gelbart, W.M., Ben-Shaul, A., Roux, D., Eds.; Springer: New York, NY, USA, 1994; pp. 485-519, ISBN 978-1-4613-8391-8. 
50. Sottmann, T.; Strey, R. Ultralow interfacial tensions in water-n-alkane-surfactant systems. J. Chem. Phys. 1997, 106, 8606-8615. [CrossRef]

51. Langevin, D.; Argillier, J.F. Interfacial behavior of asphaltenes. Adv. Colloid Interface Sci. 2016, 233, 83-93. [CrossRef]

52. Schuler, B.; Meyer, G.; Peña, D.; Mullins, O.C.; Gross, L. Unraveling the Molecular Structures of Asphaltenes by Atomic Force Microscopy. J. Am. Chem. Soc. 2015, 137, 9870-9876. [CrossRef]

53. Carnahan, N.F.; Salager, J.L.; Antón, R.; Dávila, A. Properties of resins extracted from Boscan crude oil and their effect on the stability of asphaltenes in Boscan and Hamaca crude oils. Energy Fuels 1999, 13, 309-314. [CrossRef]

54. Langevin, D.; Poteau, S.; Hénaut, I.; Argillier, J.F. Crude oil emulsion properties and their application to heavy oil transportation. Oil Gas Sci. Technol. 2004, 59, 511-521. [CrossRef]

55. Mullins, O.C.; Sabbah, H.; Eyssautier, J.; Pomerantz, A.E.; Barré, L.; Andrews, A.B.; Ruiz-Morales, Y.; Mostowfi, F.; McFarlane, R.; Goual, L. Advances in asphaltene science and the Yen-Mullins model. Energy Fuels 2012, 26, 3986-4003. [CrossRef]

56. Schuler, B.; Zhang, Y.; Liu, F.; Pomerantz, A.E.; Andrews, A.B.; Gross, L.; Pauchard, V.; Banerjee, S.; Mullins, O.C. Overview of asphaltene nanostructures and thermodynamic applications. Energy Fuels 2020, 34, 15082-15105. [CrossRef]

57. Meng, J.; You, J.B.; Hao, H.; Tan, X.; Zhang, X. Primary submicron particles from early stage asphaltene precipitation revealed in situ by total internal reflection fluorescence microscopy in a model oil system. Fuel 2021, 296, 120584. [CrossRef]

58. Goual, L.; Sedghi, M.; Wang, X.; Zhu, Z. Asphaltene aggregation and impact of alkylphenols. Langmuir 2014, 30, 5394-5403. [CrossRef]

59. Alvarez, G.; Poteau, S.; Argillier, J.F.; Langevin, D.; Salager, J.L. Heavy oil-water interfacial properties and emulsion stability: Influence of dilution. Energy Fuels 2009, 23, 294-299. [CrossRef]

60. Alvarado, J.G.; Delgado-Linares, J.G.; Forgiarini, A.M.; Salager, J.-L. Breaking of water-in-crude oil emulsions. Part 8. Demulsifier performance at optimum formulation is significantly inproved by a small aromatic content of the oil. Energy Fuels 2019, 33, 1928-1936. [CrossRef]

61. Rondón, M.; Pereira, J.C.; Bouriat, P.; Graciaa, A.; Lachaise, J.; Salager, J.-L. Breaking of water-in-crude-oil emulsions. 2. Influence of asphaltene concentration and diluent nature on demulsifier action. Energy Fuels 2008, 22, 702-707. [CrossRef]

62. Kilpatrick, P.K. Water-in-crude oil emulsion stabilization: Review and unanswered questions. Energy Fuels 2012, 26, 4017-4026. [CrossRef]

63. Zhang, Y.; Siskin, M.; Gray, M.R.; Walters, C.C.; Rodgers, R.P. Mechanisms of Asphaltene Aggregation: Puzzles and a New Hypothesis. Energy Fuels 2020, 34, 9094-9107. [CrossRef]

64. Alicke, A.; Simon, S.; Sjöblom, J.; Vermant, J. Assessing the Interfacial Activity of Insoluble Asphaltene Layers: Interfacial Rheology versus Interfacial Tension. Langmuir 2020, 36, 14942-14959. [CrossRef]

65. Svalova, A.; Walshaw, D.; Lee, C.; Demyanov, V.; Parker, N.G.; Povey, M.J.; Abbott, G.D. Estimating the asphaltene critical nanoaggregation concentration region using ultrasonic measurements and Bayesian inference. Sci. Rep. 2021, 11, 1-11. [CrossRef]

66. Acevedo, S.; Castillo, J.; Vargas, V.; Castro, A.; Delgado, O.; Cortés, F.B.; Franco, C.A.; Bouyssiere, B. Suppression of Phase Separation as a Hypothesis to Account for Nuclei or Nanoaggregate Formation by Asphaltenes in Toluene. Energy Fuels 2018, 32, 6669-6677. [CrossRef]

67. Mullins, O.C. The modified yen model. Energy Fuels 2010, 24, 2179-2207. [CrossRef]

68. Lobato, M.D.; Gámez, F.; Lago, S.; Pedrosa, J.M. The influence of the polarity of fractionated asphaltenes on their Langmuir-film properties. Fuel 2017, 200, 162-170. [CrossRef]

69. Ashoorian, S.; Javadi, A.; Hosseinpour, N.; Husein, M. Evolution of adsorbed layers of asphaltenes at oil-water interfaces: A novel experimental protocol. J. Colloid Interface Sci. 2021, 594, 80-91. [CrossRef]

70. Yeung, A.; Dabros, T.; Czarnecki, J.; Masliyah, J. On the Interfacial Properties of micrometre-sized water Droplets in Crude Oil. Proc. R. Soc. A 1999, 455, 3709. [CrossRef]

71. McLean, J.D.; Kilpatrick, P.K. Effects of asphaltene aggregation in model heptane-toluene mixtures on stability of water-in-oil emulsions. J. Colloid Interface Sci. 1997, 196, 23-34. [CrossRef] [PubMed]

72. Delgado-Linares, J.G.; Pereira, J.C.; Rondón, M.; Bullón, J.; Salager, J.L. Breaking of Water-in-Crude Oil Emulsions. 6. Estimating the Demulsifier Performance at Optimum Formulation from Both the Required Dose and the Attained Instability. Energy Fuels 2016, 30, 5483-5491. [CrossRef]

73. Delgado-Linares, J.G.; Alvarado, J.G.; Véjar, F.; Bullón, J.; Forgiarini, A.M.; Salager, J.L. Breaking of Water-in-Crude Oil Emulsions. 7. Demulsifier Performance at Optimum Formulation for Various Extended Surfactant Structures. Energy Fuels 2016, 30, 7065-7071. [CrossRef]

74. Rondón, M.; Bouriat, P.; Lachaise, J.; Salager, J.L. Breaking of water-in-crude oil emulsions. 1. Physicochemical phenomenology of demulsifier action. Energy Fuels 2006, 20, 1600-1604. [CrossRef]

75. Bourrel, M.; Passade-Boupat, N. Crude Oil Surface Active Species: Consequences for Enhanced Oil Recovery and Emulsion Stability. Energy Fuels 2018, 32, 2642-2652. [CrossRef]

76. Jeribi, M.; Almir-Assad, B.; Langevin, D.; Henaut, I.; Argillier, J.F. Adsorption kinetics of asphaltenes at liquid interfaces. J. Colloid Interface Sci. 2002, 256, 268-272. [CrossRef]

77. Dicharry, C.; Arla, D.; Sinquin, A.; Graciaa, A.; Bouriat, P. Stability of water/crude oil emulsions based on interfacial dilatational rheology. J. Colloid Interface Sci. 2006, 297, 785-791. [CrossRef] 
78. Fan, Y.; Simon, S.; Sjöblom, J. Interfacial shear rheology of asphaltenes at oil-water interface and its relation to emulsion stability: Influence of concentration, solvent aromaticity and nonionic surfactant. Colloids Surf. A Physicochem. Eng. Asp. 2010, 366, 120-128. [CrossRef]

79. Tao, J.; Shi, P.; Fang, S.; Li, K.; Zhang, H.; Duan, M. Effect of rheology properties of oil/water interface on demulsification of crude oil emulsions. Ind. Eng. Chem. Res. 2015, 54, 4851-4860. [CrossRef]

80. Sun, T.; Zhang, L.; Wang, Y.; Peng, B.; Zhao, S. Dynamic Dilational Properties of Oil-Water Interfacial Films containing Surface Active Fractions from Crude Oil. J. Dispers. Sci. Technol. 2003, 24, 699. [CrossRef]

81. Bouriat, P.; El Kerri, N.; Graciaa, A.; Lachaise, J. Properties of a two-dimensional asphaltene network at the water-cyclohexane interface deduced from dynamic tensiometry. Langmuir 2004, 20, 7459-7464. [CrossRef]

82. Aske, N.; Orr, R.; Sjöblom, J.; Kallevik, H.; Øye, G. Interfacial properties of water-Crude oil systems using the oscillating pendant drop. Correlations to asphaltene solubility by near infrared spectroscopy. J. Dispers. Sci. Technol. 2004, 25, 263-275. [CrossRef]

83. Spiecker, P.M.; Kilpatrick, P.K. Interfacial Rheology of Petroleum Asphaltenes at the Oil-Water Interface. Langmuir 2004, 20, 4022-4032. [CrossRef]

84. Yang, X.; Verruto, V.J.; Kilpatrick, P.K. Dynamic asphaltene-resin exchange at the oil/water interface: Time-dependent W/O emulsion stability for asphaltene/resin model oils. Energy Fuels 2007, 21, 1343-1349. [CrossRef]

85. Quintero, C.G.; Noïk, C.; Dalmazzone, C.; Grossiord, J.L. Formation Kinetics and Viscoelastic Properties of Water/Crude Oil Interfacial Films. Oil Gas Sci. Technol. 2009, 64, 607. [CrossRef]

86. Krawczyk, M.A.; Wasan, D.T.; Shetty, C.S. Chemical Demulsification of Petroleum Emulsions Using Oil-Soluble Demulsifiers. Ind. Eng. Chem. Res. 1991, 30, 367-375. [CrossRef]

87. Freer, E.; Yim, K.S.; Fuller, G.G.; Radke, C.J. Interfacial rheology of globular and flexible proteins at the hexadecane/water interface: Comparison of shear and dilatation deformation. J. Phys. Chem. B 2004, 108, 3835-3844. [CrossRef]

88. Yarranton, H.W.; Urrutia, P.; Sztukowski, D.M. Effect of interfacial rheology on model emulsion coalescence. II. Emulsion coalescence. J. Colloid Interface Sci. 2007, 310, 253-259. [CrossRef] [PubMed]

89. Angle, C.W.; Hua, Y. Dilational interfacial rheology for increasingly deasphalted bitumens and n-C5 asphaltenes in toluene $/ \mathrm{NaHCO}_{3}$ solution. Energy Fuels 2012, 26, 6228-6239. [CrossRef]

90. Zarkar, S.; Pauchard, V.; Farooq, U.; Couzis, A.; Banerjee, S. Interfacial properties of asphaltenes at toluene-water interfaces. Langmuir 2015, 31, 4878-4886. [CrossRef]

91. Bauget, F.; Langevin, D.; Lenormand, R. Dynamic surface properties of asphaltenes and resins at the oil—Air interface. J. Colloid Interface Sci. 2001, 239, 501-508. [CrossRef]

92. Sun, T.; Zhang, L.; Wang, Y.; Zhao, S.; Peng, B.; Li, M.; Yu, J. Influence of demulsifiers of different structures on interfacial dilational properties of an oil-water interface containing surface-active fractions from crude oil. J. Colloid Interface Sci. 2002, 255, $241-247$. [CrossRef] [PubMed]

93. Balsamo, V.; Phan, J.; Nguyen, D. Effect of diluents on interfacial properties and sagd emulsion stability: II. Differential scanning calorimetry and light scattering methods. In Proceedings of the SPE Heavy Oil Conference-Canada, Calgary, AB, Canada, 11-13 June 2013; pp. 16-26. [CrossRef]

94. Varadaraj, R.; Brons, C. Molecular Origins of Crude Oil Interfacial Activity. Part 4: Oil-Water Interface Elasticity and Crude Oil Asphaltene Films. Energy Fuels 2012, 26, 7164. [CrossRef]

95. McLean, J.D.; Kilpatrick, P.K. Effects of asphaltene solvency on stability of water-in-crude-oil emulsions. J. Colloid Interface Sci. 1997, 189, 242-253. [CrossRef]

96. Bourrel, M.; Graciaa, A.; Schechter, R.S.; Wade, W.H. The relation of emulsion stability to phase behavior and interfacial tension of surfactant systems. J. Colloid Interface Sci. 1979, 72, 161. [CrossRef]

97. Milos, F.S.; Wasan, D.T. Emulsion Stability of Surfactants Systems near the Three Phase Region. Colloids Surf. A 1982, 4, 91-96. [CrossRef]

98. Salager, J.-L.; Loaiza-Maldonado, I.; Minaňa-Perez, M.; Silva, F. Surfactant-Oil-Water Systems Near The Affinity Inversion Part I: Relationship Between Equilibrium Phase Behavior And Emulsion Type And Stability. J. Dispers. Sci. Technol. 1982, 3, $279-292$. [CrossRef]

99. Antón, R.E.; Salager, J.-L. Emulsion instability in the three-phase behavior region of surfactant-alcohoi-oil-brine systems. J. Colloid Interface Sci. 1986, 111, 54-59. [CrossRef]

100. Goldszal, A.; Bourrel, M. Demulsification of crude oil emulsions: Correlation to microemulsion phase behavior. Ind. Eng. Chem. Res. 2000, 39, 2746-2751. [CrossRef]

101. Salager, J.L.; Forgiarini, A.M.; Rondón, M.J. How to Attain Ultralow Interfacial Tension and Three-Phase Behavior with a Surfactant Formulation for Enhanced Oil Recovery: A Review-Part 3. Practical Procedures to Optimize the Laboratory Research According to the Current State of the Art in Surfactant. J. Surfactants Deterg. 2017, 20, 3-19. [CrossRef]

102. Kim, Y.H.; Wasan, D.T. Effect of Demulsifier Partitioning on the Destabilization of Water-in-Oil Emulsions. Ind. Eng. Chem. Res. 1996, 35, 1141-1149. [CrossRef]

103. Forgiarini, A.M.; Marquez, R.; Salager, J.-L. Formulation improvements in the applications of surfactant-oil-water systems using the HLDN approach with extended surfactant structure. Molecules 2021, 26, 3771. [CrossRef] [PubMed]

104. Cardenas, A.; Fillous, L.; Rouviere, J.; Salager, J. An experimental method to estimate the mass transfer through the interfacial region of liquid membrane systems. Ciencia 2001, 9, 70-76. 
105. Alvarez, G.; Antón, R.; Marfisi, S.; Márquez, L.; Salager, J.L. Apparent equilibration time required for surfactant-oil-water systems to emulsify into the morphology imposed by the formulation. Part 2: Effect of sec-butanol concentration and initial location. Langmuir 2004, 20, 5179-5181. [CrossRef] [PubMed]

106. Marfisi, S.; Rodríguez, M.P.; Alvarez, G.; Celis, M.-T.; Forgiarini, A. Complex Emulsion Inversion Pattern associated with the Partitioning of Nonionic Surfactant Mixtures in the presence of alcohol cosurfactant. Langmuir 2005, 21, 6712. [CrossRef]

107. Salager, J.-L.; Manchego, L.; Márquez, L.; Bullón, J.; Forgiarini, A. Trends to attain a lower interfacial tension in a revisited pure alkyl polyethyleneglycol surfactant-alkane-water ternary system. Basic concepts and straightforward guidelines for improving performance in enhanced oil recovery formulations. J. Surfactants Deterg. 2014, 17, 199-213. [CrossRef]

108. Berger, P.D.; Hsu, C.; Arendell, J.P. Designing and selecting demulsifiers for optimum field performance on the basis of production fluid characteristics. SPE Prod. Eng. 1988, 3, 522-526. [CrossRef]

109. Daniel-David, D.; Pezron, I.; Dalmazzone, C.; Noïk, C.; Clausse, D.; Komunjer, L. Elastic Properties of Crude Oil/Water Interface in presence of Polymeric Emulsion Breakers. Colloids Surf. A 2005, 270-271, 257. [CrossRef]

110. Mukherjee, S.; Kushnick, A.P. Effect of demulsifiers on interfacial properties governing crude oil demulsification. Prepr. Symp. 1988, 33, 205-210. [CrossRef]

111. Tambe, D.; Paulis, J.; Sharma, M.M. Factors Controlling the Stability of Colloid-Stabilized Emulsions. J. Colloid Interface Sci. 1995, 171, 463. [CrossRef]

112. Bouriat, P.; Rondón, M.; Lachaise, J.; Salager, J.L. Correlation between interfacial tension bump and optimal crude oil dehydration. Energy Fuels 2009, 23, 3998-4002. [CrossRef]

113. Kim, Y.H.; Wasan, D.T.; Breen, P.J. A study of dynamic interfacial mechanisms for demulsification of water-in-oil emulsions. Colloids Surf. A Physicochem. Eng. Asp. 1995, 95, 235-247. [CrossRef]

114. Marquez, R.; Salager, J.-L.; Langevin, D.; Forgiarini, A.M. Using the oscillatory spinning drop interfacial rheology technique as a tool to select demulsifiers according to their emulsion breaking performance at optimum formulation $(\mathrm{HLDN}=0)$. In Proceedings of the 21st International Conference Petrophase, Online Conference, USA, 7 June 2021.

115. Molaei, M.; Crocker, J.C. Interfacial microrheology and tensiometry in a miniature, 3-d printed Langmuir trough. J. Colloid Interface Sci. 2020, 560, 407-415. [CrossRef]

116. Kale, S.K.; Cope, A.J.; Goggin, D.M.; Samaniuk, J.R. A miniaturized radial Langmuir trough for simultaneous dilatational deformation and interfacial microscopy. J. Colloid Interface Sci. 2021, 582, 1085-1098. [CrossRef] [PubMed]

117. Koteich Khatib, S.; Bullón, J.; Vivas, J.; Bahsas, A.; Rosales-Oballos, Y.; Marquez, R.; Forgiarini, A.; Salager, J.L. Synthesis, Characterization, Evaluation of Interfacial Properties and Antibacterial Activities of Dicarboxylate Anacardic Acid Derivatives from Cashew Nut Shell Liquid of Anacardium occidentale L. J. Surfactants Deterg. 2020, 23, 503-512. [CrossRef] 